\title{
Modeling the gas-particle partitioning of secondary organic aerosol: the importance of liquid-liquid phase separation
}

\author{
A. Zuend and J. H. Seinfeld \\ Division of Chemistry and Chemical Engineering, California Institute of Technology, Pasadena, California, USA
}

Correspondence to: A. Zuend (zuend@caltech.edu)

Received: 10 January 2012 - Published in Atmos. Chem. Phys. Discuss.: 24 January 2012

Revised: 2 April 2012 - Accepted: 13 April 2012 - Published: 3 May 2012

\begin{abstract}
The partitioning of semivolatile organic compounds between the gas phase and aerosol particles is an important source of secondary organic aerosol (SOA). Gasparticle partitioning of organic and inorganic species is influenced by the physical state and water content of aerosols, and therefore ambient relative humidity $(\mathrm{RH})$, as well as temperature and organic loading levels. We introduce a novel combination of the thermodynamic models AIOMFAC (for liquid mixture non-ideality) and EVAPORATION (for pure compound vapor pressures) with oxidation product information from the Master Chemical Mechanism (MCM) for the computation of gas-particle partitioning of organic compounds and water. The presence and impact of a liquid-liquid phase separation in the condensed phase is calculated as a function of variations in relative humidity, organic loading levels, and associated changes in aerosol composition. We show that a complex system of water, ammonium sulfate, and SOA from the ozonolysis of $\alpha$-pinene exhibits liquid-liquid phase separation over a wide range of relative humidities (simulated from $30 \%$ to $99 \% \mathrm{RH}$ ). Since fully coupled phase separation and gas-particle partitioning calculations are computationally expensive, several simplified model approaches are tested with regard to computational costs and accuracy of predictions compared to the benchmark calculation. It is shown that forcing a liquid one-phase aerosol with or without consideration of non-ideal mixing bears the potential for vastly incorrect partitioning predictions. Assuming an ideal mixture leads to substantial overestimation of the particulate organic mass, by more than $100 \%$ at RH values of $80 \%$ and by more than $200 \%$ at RH values of $95 \%$. Moreover, the simplified one-phase cases stress two key points for accurate gas-particle partitioning calculations: (1) non-ideality in the condensed phase needs to be considered and (2) liquid-
\end{abstract}

liquid phase separation is a consequence of considerable deviations from ideal mixing in solutions containing inorganic ions and organics that cannot be ignored. Computationally much more efficient calculations relying on the assumption of a complete organic/electrolyte phase separation below a certain RH successfully reproduce gas-particle partitioning in systems in which the average oxygen-to-carbon $(\mathrm{O}: \mathrm{C})$ ratio is lower than $\sim 0.6$, as in the case of $\alpha$-pinene SOA, and bear the potential for implementation in atmospheric chemical transport models and chemistry-climate models. A full equilibrium calculation is the method of choice for accurate offline (box model) computations, where high computational costs are acceptable. Such a calculation enables the most detailed predictions of phase compositions and provides necessary information on whether assuming a complete organic/electrolyte phase separation is a good approximation for a given aerosol system. Based on the group-contribution concept of AIOMFAC and O:C ratios as a proxy for polarity and hygroscopicity of organic mixtures, the results from the $\alpha$-pinene system are also discussed from a more general point of view.

\section{Introduction}

Gas-particle partitioning is a key process in the formation and evolution of secondary organic aerosol (SOA). As a result of partitioning and coalescence, aged tropospheric aerosol particles contain mixtures of inorganic salts, acids, water, and a large variety of hydrophobic and hydrophilic organic compounds (e.g. Maria et al., 2004; Kanakidou et al., 2005; Hallquist et al., 2009). The partitioning of an organic or inorganic species between the gas phase and condensed 
particulate matter (PM) depends on a number of factors related to ambient conditions, such as temperature and relative humidity (RH), pure component volatilities, the physical state of the condensed phase, and the way in which aerosol components interact (non-ideality) (Cappa et al., 2008; Zuend et al., 2010). The driving force governing gasparticle partitioning is the progression of any natural macroscopic system towards maximum entropy at thermodynamic equilibrium.

SOA can be formed by means of gas-phase oxidation of precursor hydrocarbon compounds and subsequent gasparticle partitioning (e.g. Kroll and Seinfeld, 2008; Hallquist et al., 2009), by chemical processing of hydrophilic organics in highly dilute aqueous aerosols or cloud droplets (Ervens et al., 2004; Lim et al., 2005; Herrmann et al., 2005; Lim et al., 2010; Ervens et al., 2011), via chemical reactions and oligomer formation in aqueous, potentially acidic, organic phases (Kalberer et al., 2004; Rudich et al., 2007; Surratt et al., 2010; Camredon et al., 2010), or heterogeneous reactions on particle surfaces (e.g. Maria et al., 2004; Knopf et al., 2005).

In liquid aerosol particles, the non-ideal mixing of all species determines whether the condensed phase undergoes liquid-liquid phase separation or is stable as a single mixed phase, and whether it contains solid phases in equilibrium with their saturated solution (Zuend et al., 2010, 2011). Laboratory experiments and modeling studies suggest that a liquid-liquid phase separation into an organic-rich phase and an electrolyte-rich aqueous phase is likely present in many ambient aerosols at moderate and high $\mathrm{RH}$ (Clegg et al., 2001; Erdakos and Pankow, 2004; Marcolli and Krieger, 2006; Chang and Pankow, 2006; Anttila et al., 2007; Zuend et al., 2010; Ciobanu et al., 2009, 2010; Smith et al., 2011; Bertram et al., 2011; Song et al., 2012; Reid et al., 2011). The presence of two or more distinct liquid phases may have important consequences for multiphase chemistry, particle morphology, gas-particle partitioning, and, with respect to semisolid and amorphous solid phases, also the availability of reaction media in different physical states with potentially very different uptake and diffusivity properties.

A growing number of studies show that at lower temperatures and/or lower aerosol water contents complex organic mixtures may exist in a highly viscous semi-solid state or undergo glass transition to an amorphous solid state (e.g. Zobrist et al., 2008, 2011; Virtanen et al., 2010; Cappa and Wilson, 2011; Vaden et al., 2011; Pfrang et al., 2011; Shiraiwa et al., 2011; Pöschl, 2011; Koop et al., 2011). Such a semi-solid or amorphous solid state effectively impedes gas-particle mass transfer and bulk diffusion in aerosols with important consequences for heterogeneous chemistry, aerosol growth and evaporation behavior, and characteristic equilibration times (Tong et al., 2011; Shiraiwa et al., 2011). However, the dilution and plasticizer effects due to mixing of complex organic solutions with low-viscosity compounds like water, may substantially decrease the glass transition temperature of an initially dry mixture at higher relative humidity in case of (slightly) hygroscopic aerosols (Koop et al., 2011; Lienhard et al., 2012).

In this study, we explore the importance of liquid-liquid phase separation in aerosol particles for an accurate prediction of organic PM mass and composition by means of a novel semi-explicit gas-particle partitioning model. A complex mixture of SOA compounds from $\alpha$-pinene ozonolysis, ammonium sulfate, and water is used as a representative and atmospherically relevant system. The coupling of aerosol water content as a function of RH, non-ideal mixing thermodynamics of aqueous inorganic ions and organic compounds (salt-effect), and the resulting potential for phase separation is demonstrated. Computational aspects of gasparticle partitioning computations with and without consideration of liquid-liquid phase separation are discussed. Furthermore, we test different model simplifications with the goal to reduce computational costs while maintaining reasonable accuracy of gas-particle partitioning predictions.

\section{Theory and methods}

The modeling framework we use in this study is based on the absorptive partitioning theory (Pankow, 1994, 2003) and follows the approach of Zuend et al. (2010). A detailed description of the governing equations and the iterative numerical solution approach is given in Zuend et al. (2010). In the following, we focus on a brief description of the method, the considered combination of models within the framework and new developments.

\subsection{Gas-particle partitioning framework}

In general, gas-particle partitioning of individual chemical compounds is described by the fraction $r_{j}^{\mathrm{PM}}$ of a compound $j$ present in the condensed particulate matter phase (PM) relative to the total amount of $j$ in the gas plus aerosol system (Zuend et al., 2010):

$r_{j}^{\mathrm{PM}}=\frac{n_{j}^{\mathrm{PM}}}{n_{j}^{\mathrm{PM}}+n_{j}^{g}}=\frac{C_{j}^{\mathrm{PM}}}{C_{j}^{\mathrm{PM}}+C_{j}^{\mathrm{g}}}$.

Here, $n_{j}^{\mathrm{PM}}$ and $n_{j}^{g}$ are the molar amounts in the PM and the gas phase $g$ of the system, respectively. Analogously, $C_{j}^{\mathrm{PM}}$ and $C_{j}^{g}$ denote the mass-based concentrations ( $\mu \mathrm{g} \mathrm{m}^{-3}$ of air) in the aerosol particle and the gas phase. For a multicomponent system at gas-particle (vapor-liquid, vapor-solid) equilibrium, the vector $r_{j}^{\mathrm{PM}}(j=1, \ldots, k$ components $)$ of Eq. (1) describes the partitioning of the different species regardless of the actual partitioning mechanism at work (absorptive, adsorptive). The $r_{j}^{\mathrm{PM}}$ value of a compound in a given system reflects its volatility class. Organic compounds in the range $0.01<r_{j}^{\mathrm{PM}}<0.99$ are considered semivolatile organic compounds (SVOC) in the context of atmospheric aerosol 
terminology, as defined in Donahue et al. $(2006,2012)$. Compounds with a $r_{j}^{\mathrm{PM}}<0.01$ predominantly reside in the gas phase and are classified as intermediate volatility compounds (IVOC) or volatile organic compounds (VOC) when virtually present only in the gas phase. Compounds that predominantly reside in the condensed phase $\left(r_{j}^{\mathrm{PM}}>0.99\right)$ are classified into low volatility compounds (LVOC) and extremely low volatility compounds (ELVOC) $\left(r_{j}^{\mathrm{PM}} \approx 1.0\right)$.

Absorptive equilibrium partitioning is characterized by absorption/evaporation of condensable species by a well-mixed bulk PM phase, typically a liquid solution. Given that the gas phase can be approximated as an ideal gas mixture, at temperature $T$ the equilibrium vapor pressure of a chemical species over a liquid mixture depends on its pure liquid (potentially subcooled) vapor pressure, $p_{j}^{\circ}(T)$, and its liquid phase activity, described by modified Raoult's law (Zuend et al., 2010):

$p_{j}=p_{j}^{\circ} x_{j}^{\mathrm{PM}} \gamma_{j}^{(x)}$.

Here, $p_{j}$ is the vapor pressure over the mixture, $x_{j}^{\mathrm{PM}}$ the mole fraction of $j$ in the PM phase and $\gamma_{j}^{(x)}$ its activity coefficient on mole fraction basis (superscript $(x)$ ). In case of a liquid-liquid phase separation, Eq. (2) has to be fulfilled for each phase individually. Equation (2) can also be expressed in terms of mass concentrations:

$C_{j}^{g}=C_{j}^{\circ} x_{j}^{\mathrm{PM}} \gamma_{j}^{(x)}$,

where $C_{j}^{\circ}(T)\left(\mu \mathrm{g} \mathrm{m}^{-3}\right)$ is the pure compound gas phase saturation concentration, related to $p_{j}^{\circ}(T)(\mathrm{Pa})$ by

$C_{j}^{\circ}=\frac{p_{j}^{\circ} M_{j}}{R T} \times 10^{9} \frac{\mu \mathrm{g}}{\mathrm{kg}}$.

Here, $M_{j}\left(\mathrm{~kg} \mathrm{~mol}^{-1}\right)$ is the molar mass of compound $j$ and $R\left(\mathrm{~J} \mathrm{~K}^{-1} \mathrm{~mol}^{-1}\right)$ the universal gas constant. The factor $10^{9}$ accounts for the unit conversion.

The mole fractions and activity coefficients of the different components depend on the PM composition. Hence, the fraction of a compound partitioning to the PM phase depends also on the total available absorptive PM mass in a given system, which itself depends on the partitioning of all system components. This relationship is expressed in the mass concentration-based partitioning coefficient $C_{j}^{*}$ $\left(\mu \mathrm{g} \mathrm{m}^{-3}\right)$, called the effective saturation concentration (Donahue et al., 2006) (or its inverse, $K_{j}^{\mathrm{PM}}$, in the framework of Pankow).

$C_{j}^{*}=\frac{C_{j}^{g}}{C_{j}^{\mathrm{PM}}} \sum_{k} C_{k}^{\mathrm{PM}}$,

where the sum term on the right hand side represents the total mass concentration of the absorbing phase (i.e. including water). The $C_{j}^{*}$ values account to some extent for the effects of changes in aerosol mass loading levels and are often used as (temperature dependent) constants in simplified partitioning treatments in chemical transport models. Logarithmically spaced $C^{*}$ bins are used to represent the volatility axis in the volatility basis set (VBS) framework (Donahue et al., 2006; Robinson et al., 2007; Donahue et al., 2011, 2012). In the strict sense, however, the $C_{j}^{*}$ are not constants since (besides temperature) they also depend on changes in composition and non-ideal mixing of the PM phase. From Eqs. (3) and (5) follows:

$C_{j}^{*}=C_{j}^{\circ} \gamma_{j}^{(x)} \frac{\sum_{k} C_{k}^{\mathrm{PM}}}{M_{j} \sum_{k} \frac{C_{k}^{\mathrm{PM}}}{M_{k}}}$.

In the case of a pure compound gas-particle equilibrium $\left(\gamma_{j}^{(x)}=1\right)$, Eq. (6) simplifies to $C_{j}^{*}=C_{j}^{\circ}$. The PM phase fraction is related to $C_{j}^{*}$ and the total PM mass by

$r_{j}^{\mathrm{PM}}=\left(1+\frac{C_{j}^{*}}{\sum_{k} C_{k}^{\mathrm{PM}}}\right)^{-1}$.

Using the approximation $C_{j}^{*} \approx C_{j}^{\circ}$ and an initial guess for the total PM mass concentration, Eq. (7) yields a reasonable first guess for the set of $r_{j}^{\mathrm{PM}}$ values. Such a first guess is useful to efficiently solve the system of nonlinear equations for gas-particle equilibrium (see Zuend et al., 2010), e.g. using a globally convergent Broyden's method (Press et al., 2007) or the modified Powell's hybrid method (Moré et al., 1980, 1984).

\subsection{MCM-EVAPORATION-AIOMFAC approach}

Gas-particle partitioning calculations require knowledge of pure component properties as well as thermodynamic mixing effects, as evident from Eq. (6). We combine three specialized models to compute necessary information in a semiexplicit manner: the MCM-EVAPORATION-AIOMFAC approach.

\subsubsection{Master chemical mechanism}

The Master Chemical Mechanism (MCM), v3.1 (Jenkin et al., 1997; Saunders et al., 2003), available online: http: $/ / \mathrm{mcm}$.leeds.ac.uk/MCM, is used to simulate the chemical speciation and stoichiometric yields from the oxidation of a parent hydrocarbon ( $\alpha$-pinene) under given environmental conditions (see Sect. 3). The results from the MCM simulation are used to define a reduced set of relevant organic species, which together with water and an inorganic salt, in the present case, ammonium sulfate, chemically characterize the gas-particle system under consideration. We note that the gas-phase oxidation products of a parent hydrocarbon can be predicted by other gas-phase chemical mechanisms, and inorganic species present need not be confined to ammonium sulfate. 


\subsubsection{EVAPORATION}

Vapor pressures of pure organic compounds are calculated using the EVAPORATION model (Estimation of VApour Pressure of ORganics, Accounting for Temperature, Intramolecular, and Non-additivity effects) developed by Compernolle et al. (2011). Since pure compound vapor pressures are critical in determining the partitioning to the PM phase, uncertainties in estimated vapor pressures can have a substantial impact on the calculated total PM mass concentrations (e.g. Barley and McFiggans, 2010; McFiggans et al., 2010). EVAPORATION uses a group-contribution approach to represent the effects of different functional groups on the pure compound vapor pressure, similar to other estimation methods such as SIMPOL.1 (Pankow and Asher, 2008), but in addition also includes parameters to take intermolecular interaction and non-additivity effects into account. Here we do not evaluate the impact of using different vapor pressure estimation methods, rather we use EVAPORATION as a state-of-the-art model representing the best current estimate. In the rare cases where measurements of vapor pressures of atmospherically relevant semivolatile organics are available, e.g. for dicarboxylic acids, deviations among values reported by different groups (and measurement techniques) can span a significant pressure range, partly explained by differences related to the physical state and purity of material samples and different experimental residence times (Booth et al., 2010; Soonsin et al., 2010). Booth et al. (2010) in some cases report higher subcooled vapor pressure values for further functionalized dicarboxylic acids as compared to their parent dicarboxylic acid, e.g. in the case of 2,3-dihydroxy succinic acid and 2-keto succinic acid, which is counterintuitive to the typical behavior that further oxidation of a compound lowers the vapor pressure. In case of vapor pressure measurements referring to the solid state, Chattopadhyay and Ziemann (2005) found that keto substitutions in $\alpha$-position of a carboxyl group can raise the solid state vapor pressure of dicarboxylic acids with respect to the unsubstituted parent dicarboxylic acid, while keto substitutions at a $\beta$-position or further away from the carboxyl group, lower the solid state vapor pressure. For example, in case of glutaric acid (pentanedioic acid) they found an increase of the vapor pressure by less then an order of magnitude for 2-oxopentanedioic acid at $298 \mathrm{~K}$, yet a decrease in vapor pressure by more than an order of magnitude for 3-oxopentanedioic acid. Chattopadhyay and Ziemann (2005) suggest that a keto group in the $\alpha$-position may hydrogenbond with the carboxyl group. Hence, an internal hydrogen bond may reduce the intermolecular bonding and may lead to an increase in vapor pressure relative to the value of the unsubstituted parent dicarboxylic acid. However, such effects of vicinal functional groups in multifunctional compounds have been found only for vapor pressure measurements of samples in the solid state, while measurements of samples in the liquid state report a decrease in vapor pressure with additional ketone or hydroxyl functionalities (Frosch et al., 2010; Huisman et al., 2012). The liquid (subcooled) state vapor pressure data of Booth et al. (2010) is obtained via a thermodynamic phase state conversion from the measurements in the solid state. Uncertainties in thermochemical data used in the phase state conversion may be partly responsible for the unexpectedly high subcooled liquid vapor pressures reported by Booth et al. (2010). Compernolle et al. (2011) implemented an empirical correction term in EVAPORATION (Eq. (31) of Compernolle et al., 2011) in order to account for the findings of Booth et al. (2010), since otherwise EVAPORATION could not reproduce such effects. However, the current state of knowledge suggests that the empirical correction in EVAPORATION is in disagreement with all corresponding vapor pressure data measured for the liquid (subcooled) state. Recent measurements with the electrodynamic balance technique as used by Soonsin et al. (2010) do not support the data of Booth et al. (2010); rather, a relative decrease in (subcooled) liquid state vapor pressures of substituted compounds is found, more in line with what EVAPORATION predicts without the empirical correction (personal communication with Ulrich K. Krieger; Huisman et al., 2012). We therefore use the EVAPORATION model without the empirical correction. In addition, we note that only one compound of the $\alpha$-pinene SOA products in the current study, the ESTER_dimer (see Table 1), would be affected by the empirical correction term in EVAPORATION.

\subsubsection{AIOMFAC}

The thermodynamic group-contribution model AIOMFAC (Aerosol Inorganic-Organic Mixtures Functional groups Activity Coefficients) developed by Zuend et al. $(2008,2011)$ is used to calculate activity coefficients of the different species as a function of the liquid PM mixture composition. Positive and negative deviations of mole fraction-based activity coefficients from a value of 1 (ideal mixing), characterize for the degree of non-ideality in a mixture. AIOMFAC allows thermodynamically consistent calculations of activity coefficients at temperatures close to $298 \mathrm{~K}$ and covers multicomponent solutions containing water, inorganic ions, and organic compounds, the latter characterized in terms of combinations of functional groups. The model has recently been extended and re-parameterized to include most of the functional groups typically present in atmospheric organic compounds (Zuend et al., 2011). Additional important compound classes that have not been included in AIOMFAC to date mainly owing to the lack of experimental data to constrain interaction parameters - are the peroxide, organonitrate, and peroxy acyl nitrate functionalities.

MCM v3.1 predicts several $\alpha$-pinene oxidation products containing peroxide functionalities, therefore we implement the following new functional groups in AIOMFAC (main groups given in parenthesis): organonitrate $\left(\mathrm{CH}_{\mathrm{n}} \mathrm{ONO}_{2}\right)$, hydroperoxide $\left(\mathrm{CH}_{\mathrm{n}} \mathrm{OOH}[\right.$ perox] $)$, peroxyacid 
$(\mathrm{C}(=\mathrm{O}) \mathrm{OOH}[$ perox $])$, peroxide $\left(\mathrm{CH}_{\mathrm{n}} \mathrm{OOCH}_{\mathrm{m}}[\right.$ perox $\left.]\right)$, and peroxy acyl nitrate $\left(\mathrm{C}(=\mathrm{O}) \mathrm{OONO}_{2}[\right.$ perox] $)$. Model parameters required to describe organic $\leftrightarrow$ organic and organic $\leftrightarrow$ water interactions (the double arrow $\leftrightarrow$ indicates interactions) of the new functional groups are taken from a compatible UNIFAC model (Fredenslund et al., 1975; Hansen et al., 1991) parameterization by Compernolle et al. (2009). AIOMFAC parameters describing peroxide interactions with inorganic ions are, where applicable, estimated based on an analogy approach. A detailed description of this extension of the AIOMFAC model is given in Appendix A. These new functional groups will also be implemented into the web-version of AIOMFAC, available at http://www.aiomfac.caltech.edu.

\subsection{Liquid-liquid phase separation}

Liquid-liquid phase separation (LLPS) in the PM is a consequence of substantial non-ideal mixing to the point where the thermodynamic imperative of minimizing the free energy of a system leads to the formation of an additional phase. In electrolyte-containing aqueous organic mixtures, the high affinity of ions for water and their low affinity for organic compounds, especially their non-polar functional groups, is a typical cause for LLPS, known as the salting-out effect. If an actual liquid-liquid equilibrium (LLE) is ignored in a computation, forcing a single mixed phase, activity coefficients of both ions and organic compounds tend to become large $(\gg 1)$ and as a (incorrect) result semivolatile organics will be driven out of the mixed phase into the gas phase. The amount of polar (hydrophilic) functional groups of an organic compound relative to non-polar (hydrophobic) functional groups is a key factor in determining whether and the extent to which an aqueous organic mixture will phase separate in the presence of dissolved ions (Zuend et al., 2010).

The O:C ratio serves as a proxy parameter for polarity (Zuend et al., 2010; Donahue et al., 2011), even though it should be noted that the type of an oxygenated functional group, e.g. hydroxyl $(-\mathrm{OH})$ versus ketone $(>\mathrm{C}=\mathrm{O})$, has also an effect on the hydrophilicity and affinity for ions. Experiments show that LLPS in mixed organic-inorganic systems occurs typically for organic O:C ratios $\lesssim 0.7$ (Bertram et al., 2011; Song et al., 2012). Song et al. (2012) present experiments and AIOMFAC LLPS calculations for different aqueous mixtures of dicarboxylic acids with ammonium sulfate, showing that even quite hydrophilic dicarboxylic acids, such as 2-methylglutaric acid $(\mathrm{O}: \mathrm{C}=0.67)$, undergo a LLPS in the presence of ammonium sulfate. As the mean organic $\mathrm{O}: \mathrm{C}$ ratio decreases in the critical range from 0.67 to 0.57 , the LLPS becomes more pronounced in that it covers almost the entire composition space in terms of organic:inorganic mass ratios and the onset $\mathrm{RH}$ of phase separation shifts from $\sim 73 \%$ to $\sim 90 \%$ (Song et al., 2012). Hence, for mixtures with a mean $\mathrm{O}: \mathrm{C}<0.6$, as in this study, a LLE is expected to be the stable thermodynamic state in a wide range of the composition space and up to high relative humidity.

The method of Zuend et al. (2010) is used to minimize the Gibbs energy of the PM phase during gas-particle partitioning calculations and to determine a potential LLPS. The Gibbs energy difference between a one-phase state and a two-phase LLPS state is computed on the basis of AIOMFAC activity coefficients at a given PM composition (Zuend et al., 2010; Song et al., 2012). Numerical global minimization of Gibbs energy, as well as solving the system of nonlinear equations describing liquid-liquid equilibrium based on the isoactivity condition (Zuend et al., 2010, 2011), becomes computationally more and more demanding as the number of system components increases (\# dimensions of the problem). Therefore, the thermodynamically correct solution is expensive to compute and simplifications to such an approach will be inevitable for consideration of LLPS in large scale atmospheric models. Different ways of simplifying LLPS calculations are outlined in Sect. 2.4.

\subsection{Overview of calculation cases}

We define six calculation cases to explore the influence of non-ideality and liquid-liquid phase separation on gasparticle partitioning. The motivation for different calculation modes is to analyze potential schemes for simplified LLPS consideration in large scale models and evaluate concomitant effects on partitioning predictions in comparison to a benchmark equilibrium calculation. The six calculation cases are outlined in Fig. 1. Note that the actual morphology of phase separated particles (core-shell or partial engulfing structure) depends on the relative interfacial energies between all phases (Kwamena et al., 2010; Reid et al., 2011; Song et al., 2012) and may differ from those illustrated in Fig. 1.

Common to all calculation cases is the assumption of a liquid PM phase in the considered RH range, i.e. crystallization of both ammonium sulfate and organic compounds is ignored/suppressed as well as a potential glass transition. The "equil." case is the computationally most demanding case, because all components have to be equilibrated between all phases present. This includes a global Gibbs energy minimization to determine a potential LLPS in the PM with corresponding equilibrium compositions in all phases as a subproblem of the iterative overall gas-particle partitioning computation (the determination of the $r_{j}^{\mathrm{PM}}$ ) as introduced in Zuend et al. (2010). Note that, in all computations, metastable supersaturated salt solutions are allowed as they are of importance in aerosol particles, even though the "true" thermodynamic equilibrium would involve a crystalline salt phase instead of a supersaturated liquid.

The equil. case is defined as the benchmark case of this study and considered the most accurate solution to the actual gas-particle partitioning problem. "Accuracy" of a modeling case is here judged on the basis of the assumption 


Modeling case
equil. (benchmark case)
Full AIOMFAC LLPS computation based on
Gibbs energy minimization. Equilibration of
all components between all phases.
1-ph.
Forced one-phase computation using
AIOMFAC (non-ideal).
ideal
Ideal mixing case (Raoult's law); always a
one-phase solution.
LLPS param., non-ideal
LLPS predicted based on parameterization
of Bertram et al. (2011), using AIOMFAC
for non-ideality. Complete LLPS with
respect to organics / electrolytes.
LLPS param., ideal
LLPS predicted based on parameterization
of Bertram et al. (2011). Ideal mixing in
both phases separately. Complete LLPS
with respect to organics / electrolytes.
CLLPS, non-ideal
Complete LLPS with respect to organics /
electrolytes enforced, using AIOMFAC
(Gibbs energy difference) to determine
LLPS state.

Fig. 1. Overview of the different PM modeling cases used in the gasparticle partitioning calculations. In the situation of a liquid-liquid phase separation (LLPS), all components are allowed to partition between coexisting phases in the equilibrium case (solid arrows), while for the two different LLPS parameterization cases and the CLLPS case a complete phase separation is assumed with respect to organic compounds and electrolytes, i.e. complete separation into an aqueous organic phase and an aqueous electrolyte phase, with liquid-liquid equilibration of water only (dashed arrows). The gas phase is in all cases an ideal gas mixture equilibrating with the overall PM.

that the equil. case provides the best estimate for the physically "true" solution, since, in comparison to the simplified cases, the equil. case is least affected by additional assumptions and constraints. All of the models involved in the gasparticle partitioning and phase separation computations are subject to uncertainties. The degree of correctness of the coupled MCM-EVPORATION-AIOMFAC model is tested and discussed in the comparison of the model results to chamber data (Sect. 4.1), which is mainly a test for MCM v3.1 and EVAPORATION. In the absence of detailed and accurate measurements of the gas-particle partitioning and LLPS behavior of the full $\alpha$-pinene ozonolysis SOA + ammonium sulfate system, covering the $\mathrm{RH}$ range modeled, a direct comparison to the physically correct solution is not possible. Uncertainties related to the group-contribution prediction of activity coefficients with AIOMFAC, and related to that, the prediction of LLPS, are discussed by Zuend et al. (2011) and Song et al. (2012).
As control cases, we calculate a forced one-phase (1-ph.) solution for the PM phase using AIOMFAC activity coefficients to account for non-ideality, as well as the case of an ideal organic-inorganic mixture, where LLPS cannot occur by definition. The different shading patterns shown in Fig. 1 for ideal and non-ideal one-phase states are intended to indicate the (theoretical) difference in terms of random vs. nonrandom mixing of molecules.

Of more interest concerning simplified LLPS computation schemes are the two cases using a parameterization for the LLPS prediction and the CLLPS (complete LLPS) case based on Gibbs energy differences. The "LLPS param., nonideal" case and the "LLPS param., ideal" case both use the parameterization of Bertram et al. (2011) (Eq. 8) to decide, based on a given overall PM composition, whether a LLPS should be assumed or not.

$$
\begin{aligned}
\mathrm{RH}_{\text {LLPS }}=35.5+339.9 & (\mathrm{O}: \mathrm{C})-471.8(\mathrm{O}: \mathrm{C})^{2} \\
& \text { valid where }: 0.2<(\mathrm{O}: \mathrm{C})<0.7 \\
& \text { and } 0.1<(\text { org }: \text { sulf })<15 ;
\end{aligned}
$$$$
\mathrm{RH}_{\text {LLPS }}=0 \text {, }
$$

valid where : $0.7<(\mathrm{O}: \mathrm{C})<1.4$ and $0.1<$ (org: sulf $)<15$.

In this parameterization, $\mathrm{RH}_{\text {LLPS }}$ denotes the predicted onset relative humidity of LLPS as a function of the average organic $\mathrm{O}: \mathrm{C}$ ratio in the $\mathrm{PM}$ and the organic-to-sulfate (org:sulf) mass ratio (defining the valid range). This parameterization of Bertram et al. (2011) is based on numerous experiments of ternary organic + ammonium sulfate + water mixtures at room temperature ( $T \approx 290$ to $298 \mathrm{~K}$ ). However, at comparable $\mathrm{O}: \mathrm{C}$ ratios, different mixtures exhibit significant scatter regarding the predicted onset of phase separation (see Fig. 2 of Bertram et al., 2011), indicating that the parameterization should be considered an experimentally-based estimate (error bars of $\sim \pm 10 \% \mathrm{RH}$ ). The scattering of observed LLPS onset RH values among compounds with the same O:C might reflect effects of differences in terms of oxygenated functional group classes (e.g. hydrogen-bonding vs. non-hydrogen-bonding groups).

Common to both parameterized LLPS cases is the assumption of a complete phase separation into an aqueous organic phase and an aqueous electrolyte phase, with only water equilibrating between the two liquid phases. Hence, the organic compounds partition only between the (aqueous) organic phase and the gas phase. The assumption of a complete phase separation is partially inspired by the hydrophilic-hydrophobic phase separation approach (Pun et al., 2002; Griffin et al., 2003). However, in distinction to the hydrophilic-hydrophobic approach, in which hydrophilic organics are assumed to partition completely to the aqueous electrolyte phase, we assume all organics to partition to the organic phase. This is supported by the fact that even rather polar and hydrophilic (high $\mathrm{O}: \mathrm{C}$ ) organic compounds typically show much higher affinity for a lower O:C 
organic phase, than for a concentrated aqueous electrolyte phase. Hence, our complete phase separation approach is better characterized as an ionophilic-ionophobic phase separation. If the organic phase would consist of hydrophobic, hydrocarbon-like organics and highly oxidized, hydrophilic organics, a further phase separation of the organic phase into a low-O:C phase and a high-O:C phase could become stable. However, this is not predicted for the system in this study, since the range of organic $\mathrm{O}: \mathrm{C}$ ratios (0.3 to 0.75 ) is not large enough to cause a phase separation of the organic-rich phase.

In the "LLPS param., non-ideal" case, AIOMFAC is used to calculate activity coefficients in the two phases for a predicted LLPS or the mixed organic-inorganic one-phase state otherwise. For the "LLPS param., ideal" case, ideal mixing is assumed in both liquid phases separately, i.e. all activity coefficients set to 1.0 , while maintaining the assumption of complete organic/electrolyte phase separation. This is different from the "ideal" case, because ideal mixing is assumed only within the separated phases, hence the ideal mixtures involve compounds that are more similar in terms of polarity and hydrophilicity than when ideal mixing involving inorganic ions and organic compounds in a single phase is assumed.

Finally, the "CLLPS" case merges the assumption of complete phase separation with the concept of Gibbs energy minimization. Instead of using a parameterization to predict the onset RH of LLPS, at a given overall PM composition, the Gibbs energy difference between a one-phase and a completely phase-separated PM phase is calculated (complete LLPS with respect to organics/electolytes, as above). If the Gibbs energy of the two-phase state is lower than that of the one-phase state, LLPS is accepted. Consequently, the CLLPS case only predicts a LLPS at RH levels lower or equal to those where the equilibrium case predicts LLPS. In comparison to the "LLPS param., non-ideal" case, the CLLPS case does not rely on a parameterization that is valid only for systems containing ammonium sulfate; rather, it can be applied to any organic-inorganic system covered by AIOMFAC.

The LLPS param. and CLLPS cases are computationally far less demanding than the equil. case, because only water partitions to both liquid phases in a LLPS state. This means that for a detected LLPS the problem reduces to solving two uncoupled gas-liquid partitioning problems at given equilibrium RH (given water activity). Thus, at each iteration step in the gas-particle partitioning computation, two uncoupled 1-dimensional equations have to be solved for the water contents of the two separate liquid phases, for which reliable and efficient numerical methods exist, (e.g. Brent's method, Press et al., 2007).

\section{$3 \alpha$-Pinene ozonolysis system}

The model system for the gas-particle partitioning calculations in this study consists of 16 components: 12 selected oxidation products from the dark ozonolysis of $\alpha$-pinene, two proposed oligomers (dimers), water, and ammonium sulfate. Shilling et al. $(2008,2009)$ performed aerosol chamber simulations using MCM v3.1 for environmental conditions typical for their chamber experiments. We use their list of predicted oxidation products, lump peroxy-radical yields with related hydroperoxides and select model system compounds based on volatility. Because we are interested in compounds that likely partition to a significant degree to the condensed phase, compounds with a relatively high vapor pressure (IVOC, VOC) are not considered in the model system. The MCM-derived product distribution and selected pure compound properties from the dark ozonolysis of $\alpha$-pinene are given in Table 1. Camredon et al. (2010) propose a number of organic dimers that can form in liquid aerosols as a result of peroxyhemiacetal formation, hemiacetal formation, aldol condensation, or ester formation from $\alpha$-pinene oxidation monomers. Based on the interpretation of mass spectra and chemical reasoning, many of the suggested dimers are likely to form in liquid aerosol phases (Müller et al., 2009; Camredon et al., 2010). To study the effects of oligomers on partitioning and PM properties, we chose two dimers for our model system to represent a wider range of possible dimer structures. The "ALDOL_dimer" is formed by aldol condensation of the monomers $\mathrm{C} 108 \mathrm{OOH}$ (a $\mathrm{C}_{10}$-hydroperoxide with one aldehyde and two ketone groups) and $\mathrm{C} 89 \mathrm{CO} 2 \mathrm{H}$ (pinalic acid). The "ESTER_dimer" is one of several reaction products formed by ester formation from HOPINONIC (10-hydroxypinonic acid) and PINIC (pinic acid).

The MCM simulations of Shilling et al. (2009) show that the product distribution and corresponding compound yields vary only little with changes in parent hydrocarbon loading, so that assuming a constant product distribution for all loading levels considered is justified. In contrast to $\alpha$-pinene, other SOA precursor compounds may show considerable product variation with the hydrocarbon loading level (Chen et al., 2011). Note also that the list of MCM-predicted oxidation products may differ for other chamber simulation conditions, e.g. when shorter or longer reaction times or different $\mathrm{OH}$-radical scavengers concentrations are considered (Camredon et al., 2010; Chen et al., 2011).

Figure 2 shows the organic model system compounds (colored circles) plotted in the 2-dimensional volatility vs. O:C space (panel a) and in a Van Krevelen O:C vs. H: C diagram (panel b). Further oxidation products of either higher vapor pressures or when using different MCM simulation results from Camredon et al. (2010) are shown for comparison (open circles). Figure 2a reveals the often found correlation between volatility and $\mathrm{O}: \mathrm{C}$ ratio: products with a higher $\mathrm{O}: \mathrm{C}$ ratio have typically lower vapor pressures (unless substantial fragmentation has occurred). The two dimers chosen for the model system show that the reaction of SVOC or IVOC monomers can very effectively lower the volatility of dimers and higher oligomer products, leading to low or extremely low volatility compounds (ELVOC) even at lower 
Table 1. Oxidation products and corresponding yields predicted by the MCM model v3.1 (Jenkin et al., 1997; Saunders et al., 2003) for the dark ozonolysis of $\alpha$-pinene. List of species and corresponding stoichiometric yields are derived from the MCM chamber simulation reported by Shilling et al. (2009) for the reaction of $0.9 \mathrm{ppbv} \alpha$-pinene. Simulation conditions: $T=298.15 \mathrm{~K}, 40 \% \mathrm{RH}, 300 \mathrm{ppbv}$ ozone, $0.94 \mathrm{ppmv}$ 1-butanol, dry ammonium sulfate seed particles, and $3.4 \mathrm{~h}$ residence time. System components for the gas-particle partitioning calculations are indicated by the colored symbols (mostly non-IVOC compounds).

\begin{tabular}{|c|c|c|c|c|c|c|c|}
\hline & Name $(\mathrm{MCM})^{\mathrm{a}}$ & Structure & $M\left(\mathrm{~g} \mathrm{~mol}^{-1}\right)$ & $p^{\circ}(298.15 \mathrm{~K})(\mathrm{Pa})^{\mathrm{b}}$ & Mass yield, $\alpha^{(m) \mathrm{c}}$ & Molar yield, $\alpha^{(n)}$ & Remarks $^{d}$ \\
\hline - & $\mathrm{C} 107 \mathrm{OOH}$ & & 200.231 & $7.8328 \times 10^{-3}$ & 0.35051 & 0.23849 & $\begin{array}{l}{[\mathrm{C} 107 \mathrm{OOH}]} \\
+[\mathrm{C} 107 \mathrm{O} 2]\end{array}$ \\
\hline - & PINONIC & & 184.232 & $1.5345 \times 10^{-2}$ & 0.18951 & 0.14013 & \\
\hline \multirow[t]{2}{*}{ 口 } & $\mathrm{C} 97 \mathrm{OOH}$ & & 188.221 & $5.4035 \times 10^{-4}$ & 0.15883 & 0.11496 & $\begin{array}{l}{[\mathrm{C} 97 \mathrm{OOH}]} \\
+[\mathrm{C} 97 \mathrm{O} 2]\end{array}$ \\
\hline & PINAL & & 168.233 & $3.0798 \times 10^{0}$ & 0.10359 & 0.08389 & IVOC \\
\hline [ & $\mathrm{C} 108 \mathrm{OOH}$ & & 216.231 & $1.8447 \times 10^{-3}$ & 0.11597 & 0.07307 & $\begin{array}{l}{[\mathrm{C} 108 \mathrm{OOH}]} \\
+[\mathrm{C} 108 \mathrm{O} 2]\end{array}$ \\
\hline \multirow[t]{4}{*}{ 口 } & $\mathrm{C} 89 \mathrm{CO} 2 \mathrm{H}$ & & 170.206 & $4.6884 \times 10^{-2}$ & 0.07496 & 0.06000 & \\
\hline & $\mathrm{C} 107 \mathrm{OH}$ & & 184.232 & $7.7903 \times 10^{+1}$ & 0.05317 & 0.03932 & IVOC \\
\hline & $\mathrm{C} 96 \mathrm{OH}$ & & 156.222 & $9.8822 \times 10^{-1}$ & 0.04570 & 0.03985 & IVOC \\
\hline & NORPINAL & & 154.206 & $9.4100 \times 10^{0}$ & 0.04511 & 0.03985 & IVOC \\
\hline $\mathbf{\square}$ & PINIC & & 186.205 & $4.7358 \times 10^{-5}$ & 0.04554 & 0.03332 & \\
\hline 口 & $\mathrm{C} 921 \mathrm{OOH}$ & & 204.220 & $4.4946 \times 10^{-6}$ & 0.03662 & 0.02443 & \\
\hline \multirow[t]{3}{*}{$\mathbf{\square}$} & $\mathrm{C} 109 \mathrm{OOH}$ & & 200.231 & $1.5128 \times 10^{-2}$ & 0.02834 & 0.01928 & \\
\hline & $\mathrm{C} 96 \mathrm{OOH}$ & & 172.221 & $2.8645 \times 10^{-1}$ & 0.02614 & 0.02068 & IVOC \\
\hline & $\mathrm{C} 89 \mathrm{OOH}$ & & 158.195 & $8.7524 \times 10^{-1}$ & 0.02538 & 0.02186 & IVOC \\
\hline $\mathbf{\square}$ & $\mathrm{C} 812 \mathrm{OOH}$ & & 190.194 & $1.2132 \times 10^{-6}$ & 0.02977 & 0.02132 & \\
\hline \multirow[t]{3}{*}{$\mathbf{\square}$} & HOPINONIC & & 200.232 & $7.6498 \times 10^{-5}$ & 0.02205 & 0.01500 & \\
\hline & $\mathrm{C} 109 \mathrm{CO}$ & & 182.216 & $1.2365 \times 10^{0}$ & 0.01877 & 0.01403 & IVOC \\
\hline & $\mathrm{C} 109 \mathrm{OH}$ & & 184.232 & $6.7851 \times 10^{-2}$ & 0.01884 & 0.01393 & IVOC \\
\hline \multirow[t]{2}{*}{$\mathbf{\square}$} & $\mathrm{C} 811 \mathrm{OH}$ & & 158.094 & $3.1129 \times 10^{-3}$ & 0.01591 & 0.01371 & \\
\hline & $\mathrm{C} 721 \mathrm{CHO}$ & & 156.179 & $1.4325 \times 10^{-1}$ & 0.01572 & 0.01371 & IVOC \\
\hline 口 & $\mathrm{C} 813 \mathrm{OOH}$ & & 206.193 & $2.0391 \times 10^{-7}$ & 0.01249 & 0.00825 & \\
\hline 口 & ALDOL_dimer & & 368.421 & $1.1579 \times 10^{-11}$ & $(0)^{\mathrm{e}}$ & (0) & $\begin{array}{l}\text { dimer: } \mathrm{C} 108 \mathrm{OOH} \\
+\mathrm{C} 89 \mathrm{CO} 2 \mathrm{H}\end{array}$ \\
\hline $\mathbf{a}$ & ESTER_dimer & & 368.421 & $2.5279 \times 10^{-11}$ & (0) & (0) & $\begin{array}{l}\text { dimer: PINIC } \\
+ \text { HOPINONIC }\end{array}$ \\
\hline
\end{tabular}

a Unique compound names as assigned by the MCM model (exceptions: the dimer compounds).

${ }^{\mathrm{b}}$ Pure compound (subcooled) vapor pressure as predicted by the EVAPORATION model (Compernolle et al., 2011) without diacid correction (see Sect. 2.2.2).

${ }^{\mathrm{c}}$ Predicted stoichiometric mass yield $\alpha^{(\mathrm{m})}$ ( $\mu \mathrm{g}$ of compound formed per $\mu \mathrm{g}$ of $\alpha$-pinene reacted). The stoichiometric mass and molar yields are calculated with the assumption of

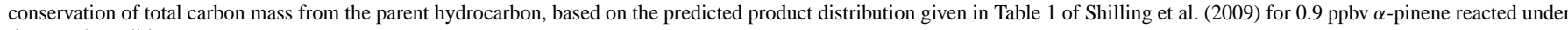
the stated conditions.

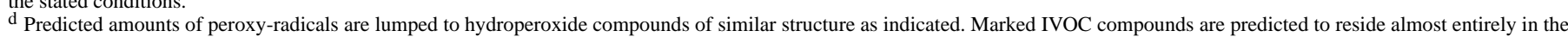
gas-phase and not considered in the partitioning calculations.

"The "ALDOL_dimer" compound (formed by aldol condensation of C108OOH + C89CO2H) and the "ESTER_dimer" compound (formed by ester formation of HOPINONIC + PINIC) are not predicted by the MCM model, rather they are assumed to form in the PM phase and related concentrations are calculated with the partitioning model, see Sect. 3. 

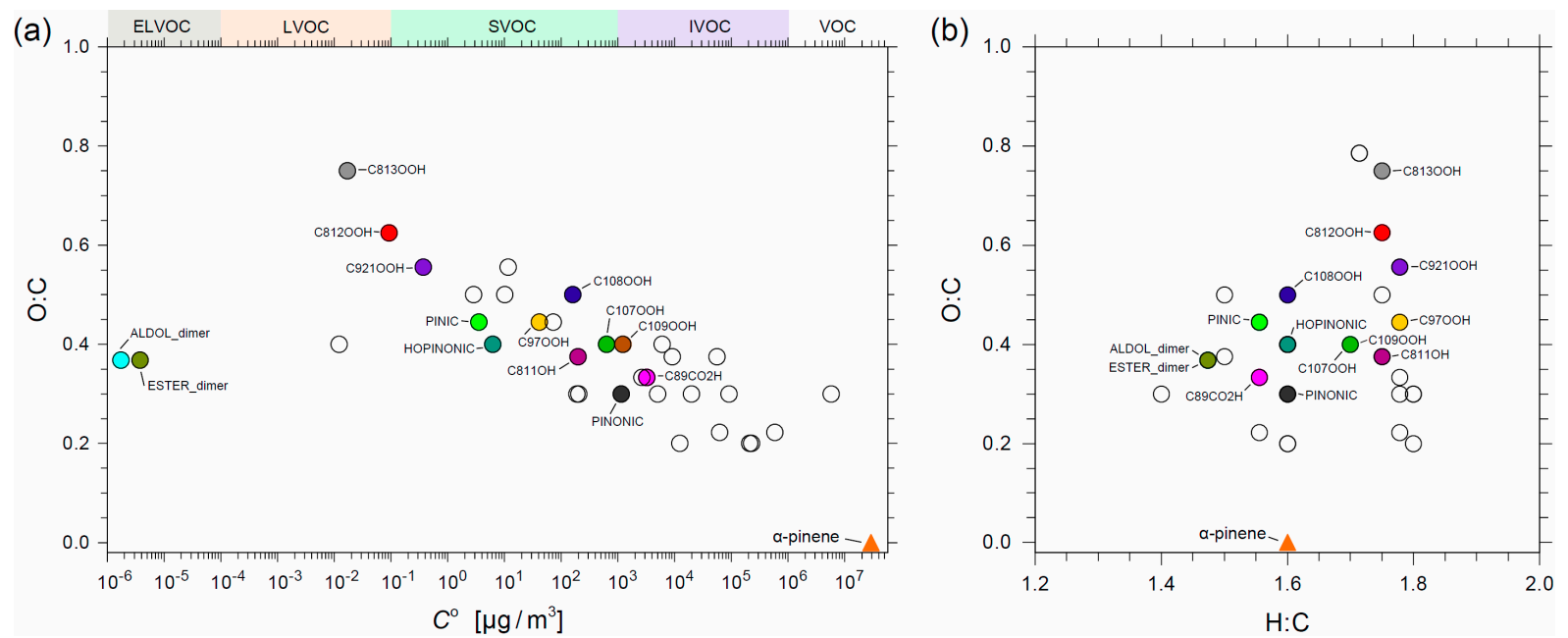

Fig. 2. (a) O:C ratio vs. volatility and (b) van Krevelen diagram (inverted) of organic compounds produced by the dark ozonolysis and further oxidation of $\alpha$-pinene. Solid colored circles show the components of the model system, open circles indicate other oxidation products of $\alpha$ pinene as predicted by MCM 3.1 for different chamber operation conditions or products at higher volatilities (IVOCs) that almost entirely reside in the gas phase (Shilling et al., 2009; Camredon et al., 2010). Pure compound saturation concentrations $\left(C^{\circ}\right)$ are calculated with the EVAPORATION model (Compernolle et al., 2011).

O:C. Hence, these dimers can be considered as virtually nonvolatile species residing completely in the particle phase.

While the MCM prediction allows the calculation of stoichiometric yields of each oxidation product relative to the amount of $\alpha$-pinene reacted (Table 1), the yields of (PMphase) oligomer products are unknown. In the absence of a quantitative prediction for the formation of the dimers or the knowledge of a dimerization equilibrium constant, we express dimer formation in a simplified manner, constrained by the molar amounts of available monomers:

$n_{d}=\lambda_{d} \min \left[n_{m 1}^{0}, n_{m 2}^{0}\right]$.

Here, $n_{d}$ is the molar amount of dimer $d$ formed, $n_{m 1}^{0}$ and $n_{m 2}^{0}$ are the initial molar amounts of parent monomers 1 and 2 , respectively, as predicted by MCM. $\lambda_{d}$ is a scaling parameter in the interval $[0,1]$ describing the fraction of monomers that reacted to form dimers with respect to the molar amount of the less abundant monomer. The resulting decrease of monomers due to dimerization follows directly from Eq. (9): $n_{m 1}=n_{m 1}^{0}-n_{d}$ and $n_{m 2}=n_{m 2}^{0}-n_{d}$. Even though dimerization is expected to occur in a liquid PM phase, at vapor-liquid equilibrium conditions the degree of dimerization can be correctly characterized by Eq. (9) based on overall (gas + PM) monomer concentrations. In this study, $\lambda_{d}$ is considered an adjustable system parameter and an actual value is assigned based on model comparison with experimental aerosol chamber data (see Sect. 4.1).

\section{Results and discussion}

\subsection{Comparison of chamber data and model results}

A measure that is routinely applied for comparison of aerosol chamber experiments conducted at different conditions is the fractional aerosol yield or SOA mass yield, $Y$, (e.g. Odum et al., 1996; Shilling et al., 2008), sometimes also called aerosol mass fraction (Pathak et al., 2007). The SOA mass yield is defined as the ratio of total organic PM mass formed $\left(\Delta C_{o r g}^{\mathrm{PM}}\right.$ ) vs. total mass of parent VOC reacted (i.e. $\Delta C_{\mathrm{VOC}}^{t}$ ):

SOA mass yield $Y=\frac{\Delta C_{\mathrm{org}}^{\mathrm{PM}}}{\Delta C_{\mathrm{VOC}}^{t}}$.

\subsubsection{SOA yield vs. loading}

The SOA mass yield is typically evaluated at the end of a chamber experiment, when all of the parent hydrocarbon has reacted. SOA mass yields of different chamber experiments reported by Shilling et al. (2008) and Chen et al. (2011) at lower hydrocarbon loadings are compared with the yields derived from our gas-particle partitioning calculations, shown in Fig. 3a. The chamber experiments use dry ammonium sulfate seed particles at $40 \% \mathrm{RH}$ and $298 \mathrm{~K}$ (see Table 1 for experimental conditions). In the presence of a liquid mixture consisting of water and organic components, a solid ammonium sulfate seed will come into equilibrium with the solution. At $298 \mathrm{~K}$ and $40 \% \mathrm{RH}$, this equilibrium is almost completely on the side of crystalline ammonium sulfate. The ammonium sulfate solubility limit, the pink curve in the calculated phase diagram shown in Fig. B1 and discussed in Appendix B, indicates that it is justified to neglect the 

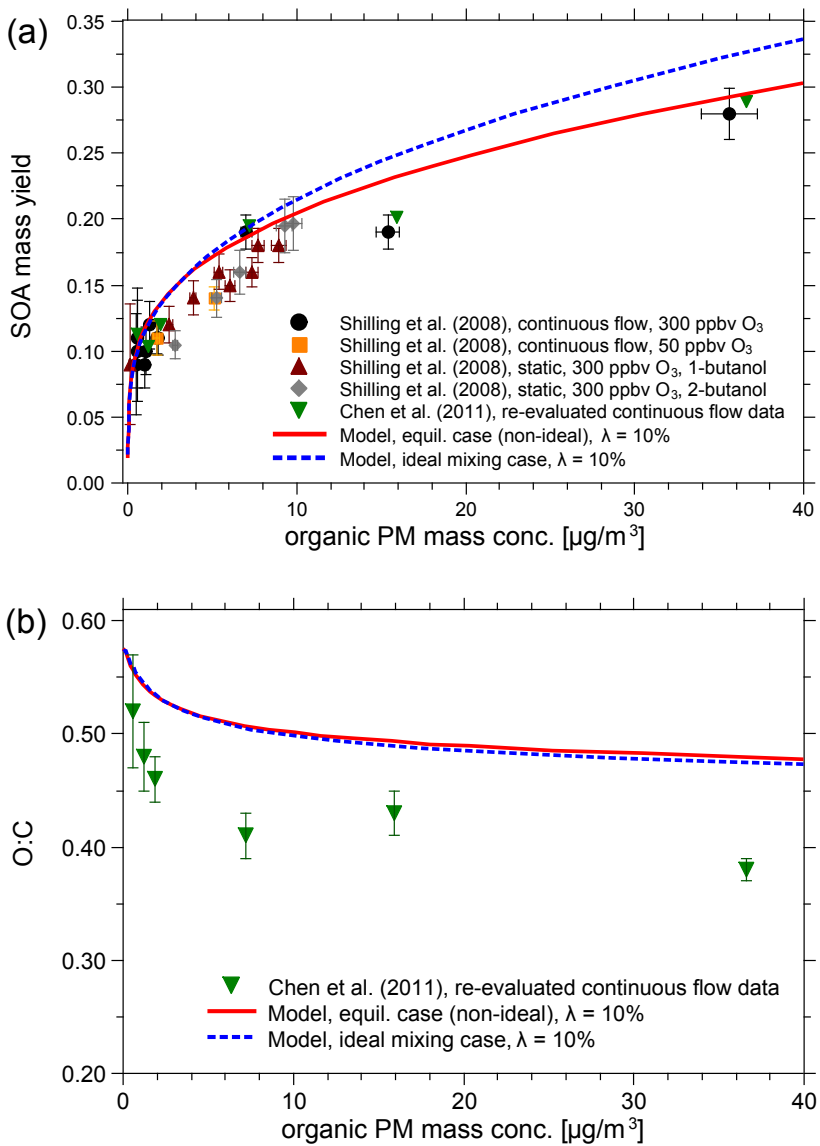

Fig. 3. Comparison of aerosol chamber data and model calculations for atmospherically relevant loading levels of $\alpha$-pinene SOA. Experimental conditions: $298 \mathrm{~K}, 40 \% \mathrm{RH}$, dry ammonium sulfate seed particles, chamber operated in continuous flow or in static "batch" mode, as described in Shilling et al. (2008). Model calculations performed at the same temperature and $\mathrm{RH}$ for the ammonium sulfatefree system using parameter $\lambda=10 \%$ for the degree of dimer formation. AIOMFAC predicts the one-phase system to be stable. (a) Measured and calculated mass yield vs. SOA mass loading. (b) Loading-dependent mean O:C atomic ratio of the organic PM mixture. Green triangles: continuous flow data at $300 \mathrm{ppbv}$ ozone of Shilling et al. $(2008,2009)$ as re-evaluated by Chen et al. (2011). Note: experimental data are not corrected for chamber wall-loss.

dissolution of the crystalline ammonium sulfate seed. Therefore, model computations corresponding to the chamber experiments were carried out for the ammonium sulfate-free 15 -component $\alpha$-pinene SOA + water system at $40 \% \mathrm{RH}$ and 298 K. For such a salt-free aqueous organic mixture, the model predicts a one-phase state as the equilibrium PM-state for all loading levels (at $40 \% \mathrm{RH}$ ).

The only adjustable model parameters are the degrees of dimer formation represented by parameters $\lambda_{\text {ALDOL_dimer }}$ and $\lambda_{\text {ESTER_dimer }}$ (Eq. 9). In the absence of more rigorous constraints, we choose a single dimerization parameter $\lambda=$ $\lambda_{\text {ALDOL_dimer }}=\lambda_{\text {ESTER_dimer }}$. A series of test-calculations suggest that the measured SOA yields of Shilling et al. (2008) are best represented for values of $\lambda$ in the range $1 \%<\lambda<$ $20 \%$. Therefore, a fixed value of $\lambda=10 \%$ is used for all model calculations in this study. Setting $\lambda=0 \%$, i.e. no dimerization, results in predicted yields that are at the lower limit of the measured yields, while setting $\lambda=100 \%$ clearly overpredicts the measured SOA mass yields. For example, at $10 \mu \mathrm{g} \mathrm{m}^{-3}$ SOA mass conc. a SOA mass yield of 0.34 is calculated for $\lambda=100 \%$ while the calculated SOA mass yield is 0.21 for $\lambda=10 \%$. In reality, the degree of dimer formation will also depend on the PM composition and therefore also depend on the SOA loading level. Such a more complex dependence is ignored here due to the lack of experimental constraints. Note that the chamber data shown in Fig. 3 are not corrected for wall-loss, which would shift measured yields slightly upwards, especially at higher organic PM mass concentrations. However, Shilling et al. (2008) show that their wall-loss corrected data at lower loading levels (org. PM mass conc. $<10 \mu \mathrm{g} \mathrm{m}^{-3}$ ) are within the error of the uncorrected data.

As discussed in Shilling et al. (2008), there is quite some variation in reported SOA yields from $\alpha$-pinene ozonolysis experiments performed by different research groups in different chambers, which are partly explained by differences in chamber operation, such as different temperatures, residence times, RH, and radical scavengers. Our model results agree more closely with the comparably higher yields reported in the literature (e.g. Song et al., 2007; Shilling et al., 2008), than with the lower yields of other experiments (e.g. Cocker et al., 2001; Pathak et al., 2007).

Figure 3a shows the generally good agreement between measured and modeled SOA mass yields at atmospherically relevant organic PM mass concentrations. We performed an equil. case and an ideal mixing case calculation, which both agree very well at lower organic PM mass concentrations, but deviations between the two calculation cases become evident at higher loading levels. The reasons for such good agreement, and therefore limited influence of non-ideality in the salt-free system at $40 \% \mathrm{RH}$, are that the organics in the PM mixture are relatively similar in terms of hydrophilicity (O:C) and especially at lower loading levels also show a higher average $\mathrm{O}: \mathrm{C}$ ratio and hence only moderate nonideal mixing with water. However, as we show below for the ammonium sulfate-containing system, non-ideality becomes very important as soon as a dissolved electrolyte is present in the PM and/or when higher RH levels (higher PM water content) are considered. The agreement between predicted and measured SOA yields is a remarkable demonstration of the applicability of the MCM-EVAPORATIONAIOMFAC modeling approach. Since non-ideality is not an important factor in the salt-free case at $40 \% \mathrm{RH}$, it means that the species and amounts predicted by MCM v3.1 as well as the vapor pressures predicted by EVAPORATION are very good estimations, as they constitute the main impact on the model results. Hence, the comparison of the model results to 
chamber data provides mainly a validation of the accuracy of MCM v3.1 and EVAPORATION for an aqueous organic onephase system. Note also that the tuning capability of our approach by setting the dimerization parameter $\lambda$ is limited and could not compensate for systematically over- or underpredicted vapor pressures on the order of factors $>2$. On the contrary, in many cases reported in the literature, predicted vapor pressures of organic (surrogate) compounds had to be tuned up or down by factors of up to 100 to achieve agreement between modeled and measured yields (e.g. Cocker et al., 2001; Jenkin, 2004; Valorso et al., 2011).

\subsubsection{Oxygen-to-carbon ratio}

Comparisons of measured and modeled SOA mass yields only reflect overall gas-particle partitioning behavior, but do not reveal a more detailed picture in terms of individual compound partitioning and phase compositions. An additional routinely measured PM phase parameter is the average organic O:C ratio in the PM, which we compare to the model results in Fig. 3b. The average O:C ratio presents additional information to evaluate model predictions more related to the chemical composition of the organic PM. Figure $3 \mathrm{~b}$ shows that the model systematically overpredicts the mean $\mathrm{O}: \mathrm{C}$ (positive deviation of 0.03 to 0.1 in $\mathrm{O}: \mathrm{C}$ ), while the general behavior as a function of organic PM mass loading is reproduced well. Chen et al. (2011) found similar results for their model calculations using MCM and SIMPOL (Pankow and Asher, 2008). They discuss possible reasons for the higher O:C ratios predicted with the model. One possibility to reduce organic $\mathrm{O}: \mathrm{C}$ while not substantially altering the SOA yield is through particle-phase oligomer formation from LVOC monomers via aldol condensation or ester formation and related dehydration. Another potentially important mechanism involves the PM phase decomposition of unstable hydroperoxides by photolysis or thermolysis and subsequent PM phase radical reactions and dehydration (Chen et al., 2011). Both proposed reaction pathways would eventually lead to a decrease in (predicted) $\mathrm{O}: \mathrm{C}$ (and $\mathrm{H}: \mathrm{C}$ ) and could reduce deviations between model and measurements. Figure 2 also suggests that additional formation of dimers from low-O:C IVOCs and SVOCs could lead to a lower overall O:C. For example, at a SOA mass concentration of $10 \mu \mathrm{g} \mathrm{m}^{-3}$ (and $\lambda=10 \%$ ), the predicted average organic O:C ratio in the PM is 0.51 , while in the gas phase the average organic O:C is 0.35 . Hence, enhanced partitioning of IVOCs (as dimers / oligomers) to the PM has the potential to lower the average O:C of SOA to a value in better agreement with the experimental data. However, efficient dimerization involving IVOCs would also enhance the SOA yield, which in the current model system is already partly represented by the two dimers in terms of the assigned dimerization degree. This discussion shows that particle-phase chemistry and oligomer formation may be important processes that are currently not explicitly considered in partitioning models. Overall, consid- ering all assumptions and simplifications involved in the gasparticle partitioning model, as well as uncertainties regarding experimental data, the MCM-EVAPORATION-AIOMFAC approach is quite successful in predicting a reasonable PM mass and composition with only minimal model tuning.

\subsection{Phase separation and RH-dependence in salt-containing system}

In the following, results for the full gas-aerosol model system calculations including ammonium sulfate are discussed. In the presence of dissolved inorganic ions, the consideration of non-ideality in liquid mixtures becomes important (Zuend et al., 2010). Since the composition range of a LLPS and the effects of non-ideal mixing on PM hygroscopicity (water content) depend on relative humidity, we model the partitioning behavior over a RH range from $30 \%$ to $99 \%$ at a constant temperature of $298 \mathrm{~K}$. This represents the $\mathrm{RH}$ range, for which the assumption of a liquid PM phase is justified when starting from a high RH level, as crystallization (efflorescence) of ammonium sulfate in aqueous solutions typically occurs in the range of $40 \%$ to $25 \%$ RH (Ciobanu et al., 2009, 2010; Bertram et al., 2011; Song et al., 2012). A transition of a liquid PM to a semi-solid or amorphous solid state is also more likely to occur at lower RH (below the $30 \%$ $\mathrm{RH}$ range boundary), due to the plasticizer effect of water on the glass transition of partially hygroscopic organic mixtures (e.g. Koop et al., 2011; Lienhard et al., 2012). To address effects of PM mass on gas-particle partitioning, three atmospherically relevant SOA mass loading levels are considered: high loading $\left(\sim 23 \mu \mathrm{g} \mathrm{m}^{-3}\right)$, moderate loading $\left(\sim 5 \mu \mathrm{g} \mathrm{m}^{-3}\right)$, and low loading $\left(\sim 0.9 \mu \mathrm{g} \mathrm{m}^{-3}\right)$ of SOA. The corresponding $\mathrm{O}: \mathrm{C}$ ratios of the SOA at $60 \% \mathrm{RH}$ are $0.48,0.51$, and 0.55 at high, moderate, and low loading levels, respectively. The predicted O:C ratios remain almost constant over the considered RH range (variation of \pm 0.01 ), with slightly lower values at higher RH. The ammonium sulfate concentrations are kept constant for all SOA loading levels at a value of $2.64 \mu \mathrm{g} \mathrm{m}^{-3}$ $\left(2.0 \times 10^{-8} \mathrm{~mol} \mathrm{~m}^{-3}\right)$ and the salt is treated as a non-volatile component. The three different loading levels represent cases of high, moderate, and low air pollution with respect to submicron aerosol particles $\left(\mathrm{PM}_{1.0}\right)$.

\subsubsection{Phase compositions}

Panels (a), (b), and (c) of Fig. 4 show the phase compositions predicted by the equil. case calculations as a function of RH (at equilibrium: RH $=$ PM water activity, $a_{\mathrm{w}}$ ). For clarity, the water contents of the phases are not shown (indicated as water-free, w-f), because water would dominate the gas phase composition by far and also be the major constituent of the electrolyte-rich PM phase at high RH. As an example, liquid water contents of the two PM phases at $60 \% \mathrm{RH}$ and compound partitioning as a function of saturation concentration are shown in panels (d), (e), and (f) of Fig. 4. 

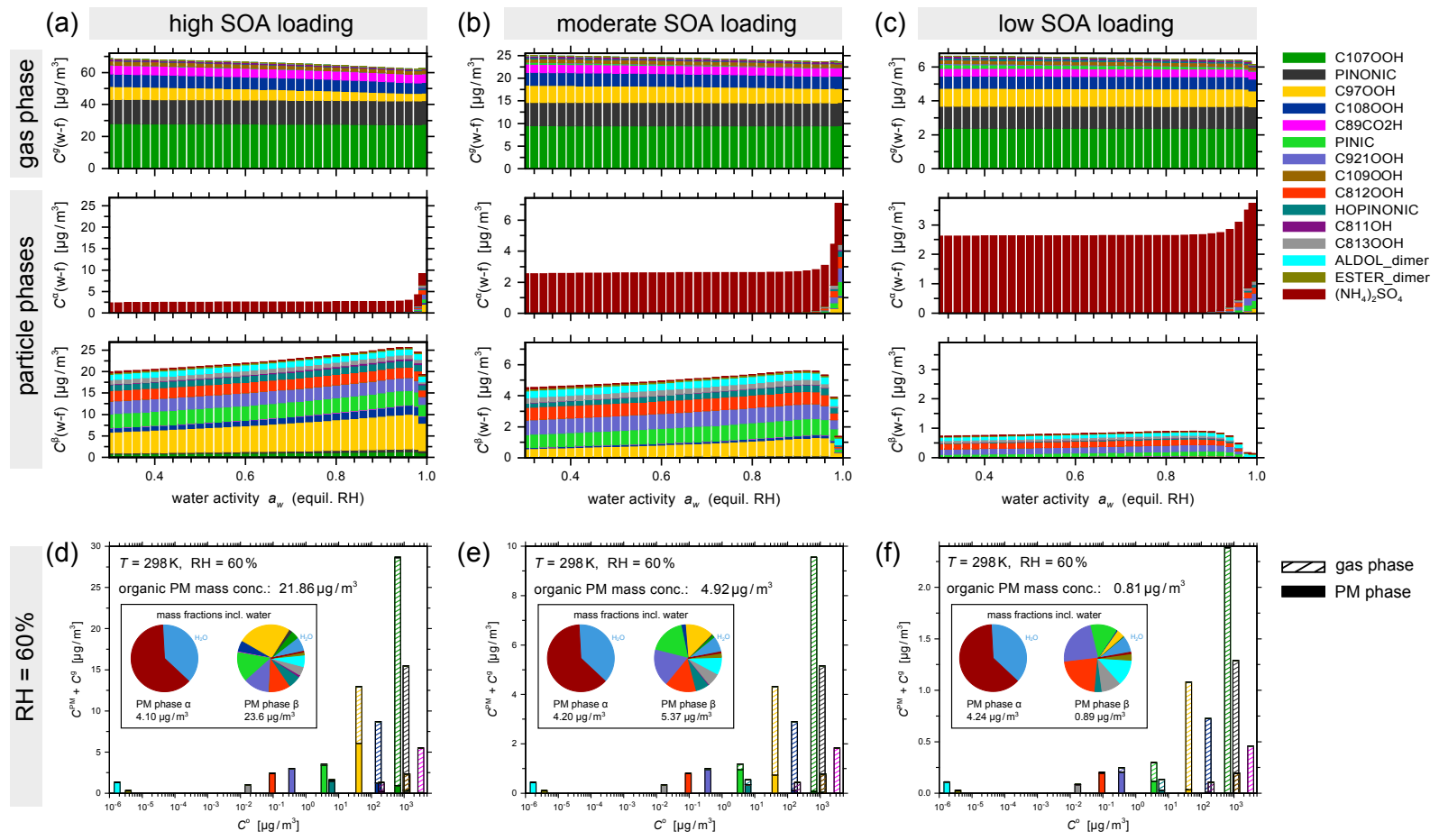

Fig. 4. Calculated gas and particle phase compositions as a function of RH (30\% to 99\%) at different SOA loading levels. All computations are for the benchmark equilibrium modeling case at $298 \mathrm{~K}$. Top panels $(\mathbf{a}, \mathbf{b}, \mathbf{c})$ : water-free phase compositions in terms of mass concentrations per unit volume of air. At all water activities (= equilibrium RH) and SOA loading levels, the model predicts a liquid-liquid phase separation of the PM into a predominantely aqueous ammonium sulfate phase $\alpha$ and a predominantely aqueous organic phase $\beta$. Bottom panels (d, e, f): the gas-particle partitioning of each organic compound at $60 \% \mathrm{RH}$ as a function of the SOA loading level and its pure compound saturation concentration $C^{\circ}$. The pie-charts (insets) reveal the mass fractions of water associated with the two liquid phases.

The model predicts a LLPS over the entire RH range shown, as evident from the unequal compositions of the two liquid PM phases - denoted as aqueous electrolyterich phase, $\alpha$, and aqueous organic-rich phase, $\beta$. The total heights of the composition bars on the mass concentration scale also indicate size ("dry" mass) differences between the two phases. Note the different concentration-axis scalings for different loading levels. For example, the organic-rich phase at $98 \% \mathrm{RH}$ and low SOA loading is much smaller than the electrolyte-rich phase, and considering the much higher water-content of phase $\alpha$, phase $\beta$ will only form a relatively small phase, probably lens-shaped or as a thin coating (Reid et al., 2011), on a largely aqueous organic-inorganic droplet. In this case it is also interesting to note that due to the high RH, i.e. dilute aqueous conditions, and a large volume difference between the PM phases, the majority of organics actually partition to phase $\alpha$, and in turn phase $\beta$ consists of low-O:C compounds only. Similar LLPS partitioning behavior is also found for moderate and high SOA loadings at high RH. Due to the hygroscopicity of ammonium sulfate, the water content of the total PM decreases steeply from $99 \%$ to $\sim 90 \% \mathrm{RH}$, while in parallel phase separating organic-inorganic interactions become more dominant, leading to a nearly complete organic/electrolyte phase separation at $\lesssim 90 \%$ RH. Neither the salt-free organics + water system nor the organic-free ammonium sulfate + water system undergoes LLPS in the RH range shown. Thus, the LLPS is a result of interactions of SOA compounds with $\mathrm{NH}_{4}^{+}$and $\mathrm{SO}_{4}^{2-}$ ions and their competition for $\mathrm{H}_{2} \mathrm{O}$ as a common solvent. Thus, while the SOA from $\alpha$-pinene would classify as water-soluble organic carbon (WSOC) (e.g. Sullivan and Weber, 2006), it does not mean that WSOC compounds partition preferentially to what is commonly called the "aqueous phase"; rather, the concentration of dissolved inorganic ions in the aqueous electrolyte-rich phase will be a key influence and most often prevent WSOC from partitioning substantially to the aqueous phase.

\subsubsection{Loading effects and water content}

The SOA loading effect on gas-particle partitioning is clearly visible form the changes in the particle fractions of the semivolatile compounds PINIC (light green) and $\mathrm{C} 97 \mathrm{OOH}$ (yellow). For example, the bar graphs in the bottom panels of Fig. 4 show how PINIC partitions predominantly to the PM phase at high loading, is mostly found in the PM phase at moderate loading ( $80 \%)$, and is found in substantial amounts in both the PM and gas phases at low loading (40\% 
in PM phase). The RH dependency of such mass loading effects on the different organic compounds is also depicted in Fig. 6, discussed further below. The mass fraction of water is nearly unaffected by changes in SOA loading, shown in the pie-charts of panels (d), (e), and (f) of Fig. 4 at $\mathrm{RH}=60 \%$. This is, of course, expected for the electrolyte-rich phase, as the mass fraction of water for a given amount of ammonium sulfate at a given $\mathrm{RH}$ is fixed (when the organic contents are negligible). However, also the water fraction in the organicrich phase is only slightly affected by the SOA loading, indicating that the hygroscopicity of the organic mixture does change only slightly, i.e. the average organic O:C does not change by much $(\mathrm{O}: \mathrm{C}=\sim 0.48, \sim 0.51$, and $\sim 0.55$ at high, moderate, and low loading levels, respectively), even when the mass fractions of some of the SVOCs change significantly with changes in mass loading. This is not a general feature of organic phases, but for $\alpha$-pinene SOA at moderate $\mathrm{RH}$ it is the case. It should also be noted that the water content in terms of mass fractions appears as relatively low, due to the large difference in molar mass of $\mathrm{H}_{2} \mathrm{O}$ compared to the organics; the water content in terms of mole fractions is much higher: $\sim 50 \%$ in the organic phase at $60 \% \mathrm{RH}$ and $\sim 38 \%$ at $40 \% \mathrm{RH}$. This is enough water to significantly influence the overall viscosity in the organic phase and prevent a glass transition, at least at higher relative humidities (Koop et al., 2011; Lienhard et al., 2012).

\subsection{Evaluation of simplified modeling cases}

As introduced in Sect. 2.4, it is of interest to evaluate the extent to which simplified gas-particle partitioning models can reproduce the results of the demanding equil. case calculations. Figure 5 presents a comparison of all calculation cases with the benchmark equil. case for the prediction of total PM mass concentrations (summed over all components and all PM phases), as well as the total organic PM mass concentrations. Since below $\sim 90 \%$ RH predicted LLPS are nearly complete organic/electrolyte phase separations (equil. case) or defined to be completely separated (LLPS param. cases, CLLPS case), the red "organics only" curves essentially represent water-free mass concentrations of the organic-rich phase in the modeling cases where LLPS is considered/predicted. At all loading levels, the equil. case shows only a relatively small positive change of total organic PM mass with an increase in RH, mainly due to only moderate hygroscopicity of organic compounds with mean $\mathrm{O}: \mathrm{C}$ around 0.5. The total PM mass (including water and $\left.\left(\mathrm{NH}_{4}\right)_{2} \mathrm{SO}_{4}\right)$ shows a much higher dependency on $\mathrm{RH}$, with a very steep increase in PM mass due to large water uptake at high RH. Hence, the water uptake follows primarily the hygroscopic growth behavior of ammonium sulfate.

Figure 6 shows the effects of RH and loading level on the gas-particle partitioning of the individual organic compounds. This allows a closer look at how the different simplified modeling cases affect semivolatile compound partition- ing and how this relates to modeling case-dependent changes of total organic PM as shown in Fig. 5. However, the accumulated organic PM concentrations shown as red curves in Fig. 5 depend not only on the changes in compound-specific organic PM phase fractions, but also on the total system concentrations of those compounds. Hence, a large change in the $r_{j}^{\mathrm{PM}}$ of a compound may not translate into a noticeable PM mass change if the compound is only a minor component of the system.

Figure 7 compares calculated $C_{j}^{*}$ values of all organic compounds at the different loading levels. Over a wide RH range up to $\sim 90 \%, C_{j}^{*}$ values according to the benchmark case show relatively little variation with a nearly constant slope on the logarithmic scale. Since the definition of $C_{j}^{*}$ based on Eq. 5 includes PM water (and ammonium sulfate) in the summed $C_{k}^{\mathrm{PM}}$ term (Zuend et al., 2010), the large water uptake at $\mathrm{RH}>90 \%$ affects the effective saturation concentrations, especially prominent for low-O:C compounds. Figure 6 shows that at high $\mathrm{RH}$ all SOA compounds exhibit enhanced partitioning to the PM phase on an absolute scale, due to high dilution with water. On a relative scale, Fig. 7 suggests that the high water content also enhances the partitioning of low-O:C compounds (e.g. PINONIC, $\mathrm{O}: \mathrm{C}=0.3$ ) to the gas phase - relative to higher-O:C compounds (e.g. $\mathrm{C} 813 \mathrm{OOH}, \mathrm{O}: \mathrm{C}=0.75$ ), partially counteracting the dilution effect.

\subsubsection{Forced non-ideal and ideal one-phase cases}

The top row panels of Fig. 5 show that neither the assumption of an ideal mixture nor forcing a (non-ideal) one-phase PM is a good simplification in the presence of ammonium sulfate. The forced 1-ph. case succeeds in approximating the equil. case results at high SOA loading, because in that case the organic fraction is much larger than the amount of $\left(\mathrm{NH}_{4}\right)_{2} \mathrm{SO}_{4}$, so that the influence of organic $\leftrightarrow$ ion interactions is diminished. However, at moderate and low loading, the organic PM mass is not reproduced - in fact, at low loading and RH below $\sim 80 \%$, the salting-out effect is predominant and eventually drives all organics out of the condensed phase to the gas phase; see also Figs. 6c and 7c. Hence, the effects of non-ideal mixing, which trigger LLPS in the equilibrium case, are evident from the comparison with the forced one-phase case shown in the top rows of Figs. 5 and 6. Note that in the forced 1-ph. case effects of non-ideal mixing are mainly controlled by the "dry" ratio (water-free basis) of organics:inorganics, this includes the extent to which the organic compounds are salted out to the gas phase. At $60 \% \mathrm{RH}$ and $298 \mathrm{~K}$, the equilibrium case calculations predict the following mass fractions of ammonium sulfate in the dry (water-free) overall PM mixture, $\operatorname{mf}_{d}(\mathrm{AS}): \sim 0.108, \sim 0.349$, and $\sim 0.766$, for high, moderate, and low SOA loading, respectively. At higher ratios of organic:inorganic mass fractions (lower values of $\mathrm{mf}_{d}(\mathrm{AS})$ ), the forced 1-ph. case agrees better with the results from the equilibrium case, because the 

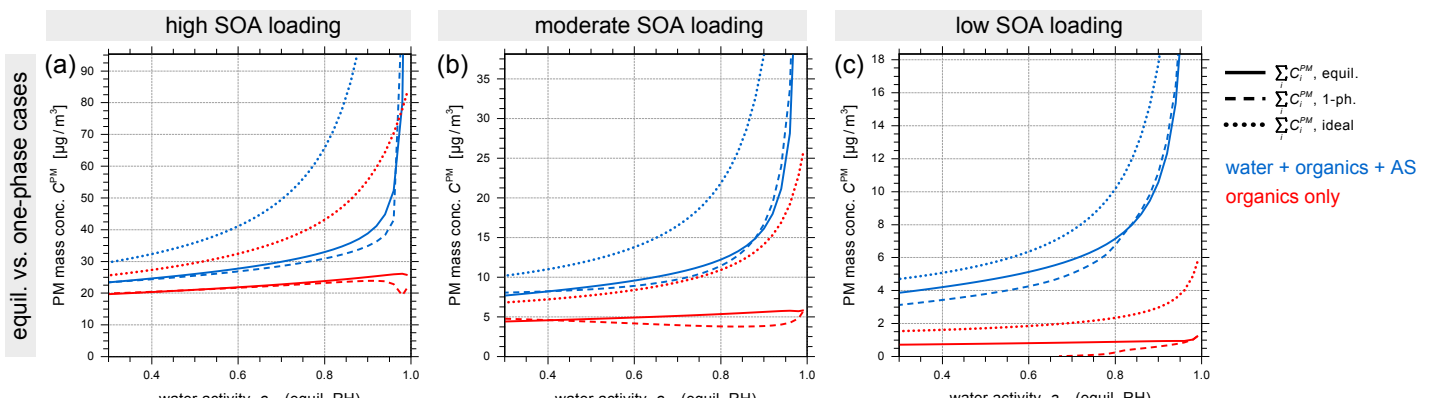

water + organics +
organics only

water activity $a_{w}$ (equil. $\mathrm{RH}$ )
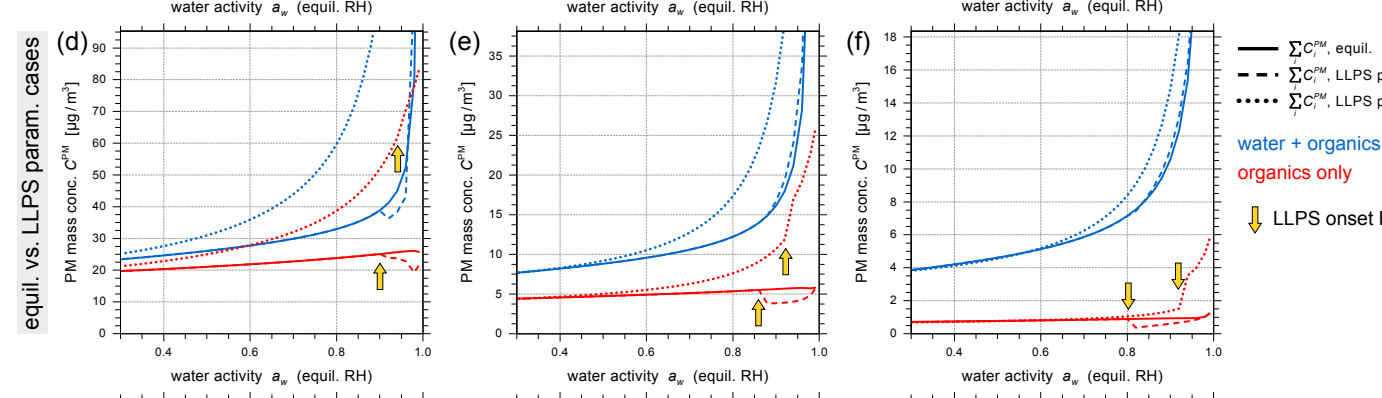

- - $\sum_{i} C_{i}^{p M}$, LLPS param., non-ideal

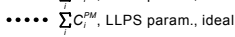

water + organics + AS

organics only

תLLPS onset RH
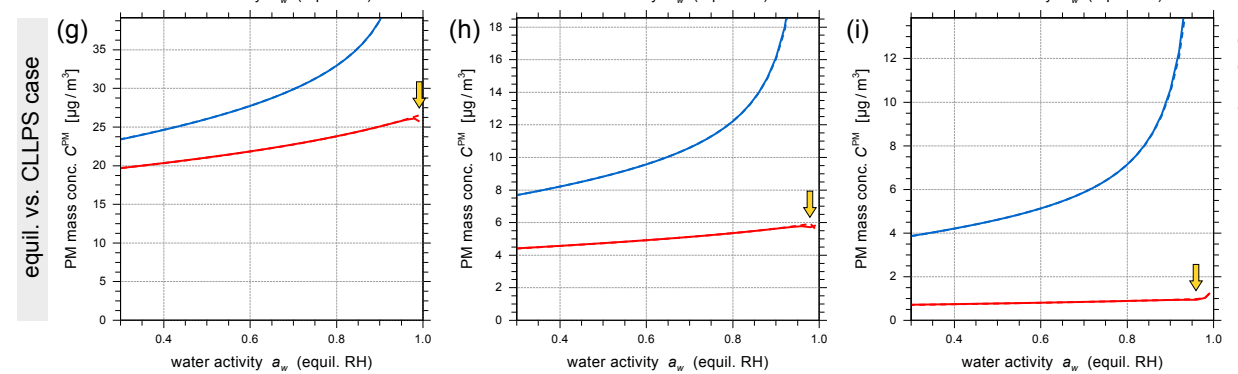

$-\sum_{j} C_{i}^{p M}$, equil.
$--\cdot \sum_{i}^{P_{i} M}$, CLLPS, non-ideal

water + organics + AS

organics only

Fig. 5. Total particulate matter (PM) concentrations (blue curves) and total organic PM concentrations (organic PM fraction; red curves) plotted as a function of RH at $298 \mathrm{~K}$. The different modeling cases are compared with the benchmark (equil.) case at three distinct SOA loading levels. Top row (a, b, c): comparison of the forced one-phase case (1-ph., dashed curves) and the ideal mixing case (dotted curves) with the equil. case (solid curves in all panels). Middle row (d, e, f): comparison of the non-ideal (dashed curves) and ideal (dotted curves) LLPS param. cases with the benchmark case. The phase separation onset RH is calculated using the parameterization of Bertram et al. (2011). The yellow arrows mark the calculated upper RH limit of liquid-liquid phase separation for the parameterized cases (responsible for the kinks in the curves). Bottom row (g, h, i): comparison of the complete phase separation CLLPS case with the benchmark case. AIOMFAC is used to compute activity coefficients in all cases where non-ideal mixing is considered.

salting-out effect is less pronounced. For example, if in a calculation the amount of ammonium sulfate is highly reduced in the low SOA loading system to match the dry organic:inorganic ratio of the high SOA loading system, i.e. $\operatorname{mf}_{d}($ AS) $=\sim 0.108$ (organic:ammonium sulfate mass ratio of $\sim 8.27$ ), the results of the forced 1-ph. case agree much better with the equil. case. However, in atmospheric aerosols the dry ratio of organic:inorganic components is neither constant nor generally known, so that forcing a single liquid phase may be reasonable only under certain conditions, which depend on $\mathrm{mf}_{d}(\mathrm{AS})$ as well as the miscibility of the organic fraction with aqueous inorganic ions.

Assuming ideal mixing leads to an RH dependency that is very different from the actual behavior, because in an ideal mixture the apparent "hygroscopicity" of all inorganic and organic molecules is indistinguishable. This substantially alters the compound partitioning behavior shown in Fig. $6 \mathrm{~d}-\mathrm{f}$.
In contrast to the equil. case, all organic components with volatilities at the upper limit of the SVOC category and even IVOCs manifest high PM phase fractions at high RH. This leads to huge PM mass concentration deviations at high RH compared to the benchmark results. In general, the ideal case predicts substantially higher organic PM mass concentrations than the equil. case, e.g. at moderate SOA loading: overprediction by $+71 \%$ at $60 \% \mathrm{RH},+104 \%$ at $80 \% \mathrm{RH}$, and $+214 \%$ at $95 \% \mathrm{RH}$.

Based on these obvious discrepancies, both forcing a nonideal one-phase state or an ideal mixture bear the potential for vastly incorrect partitioning predictions. Moreover, these simplified approaches stress two key points for accurate gasparticle partitioning calculations: (1) non-ideality in the condensed phase needs to be considered and (2) LLPS is a consequence of considerable deviations from ideal mixing in 

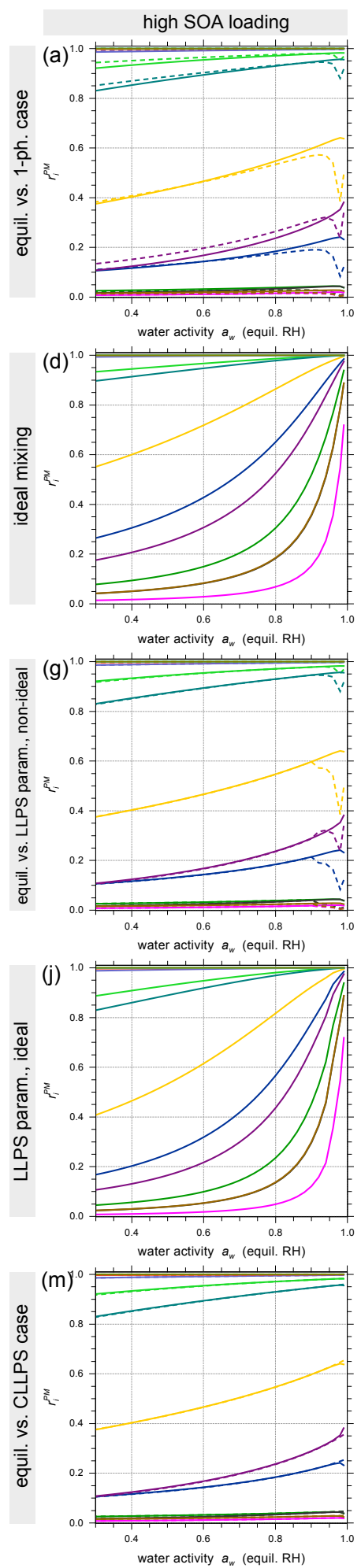
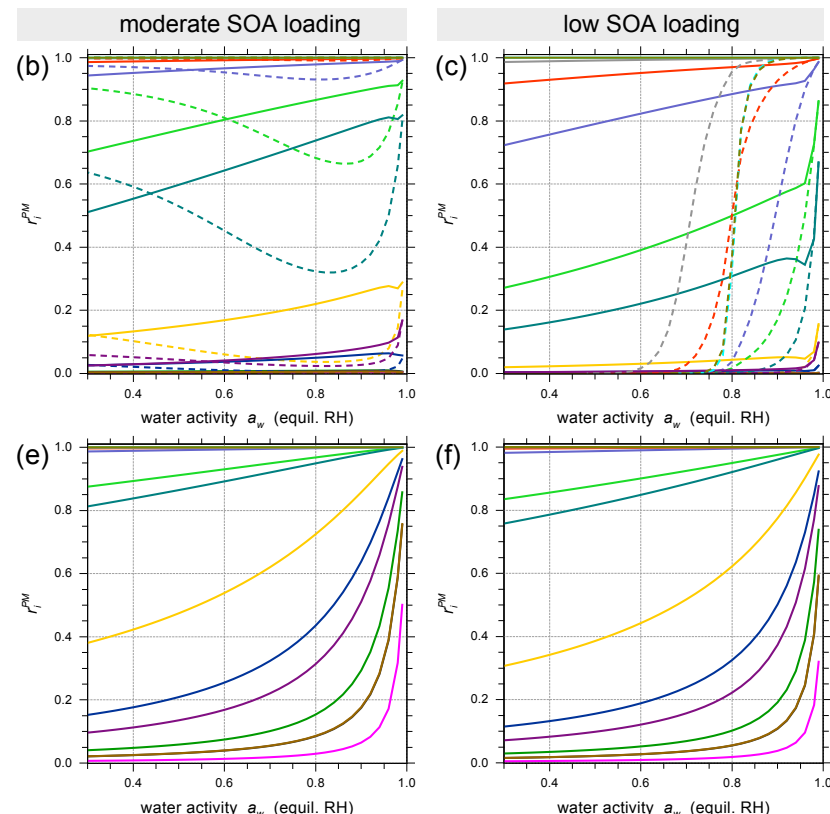

(f)
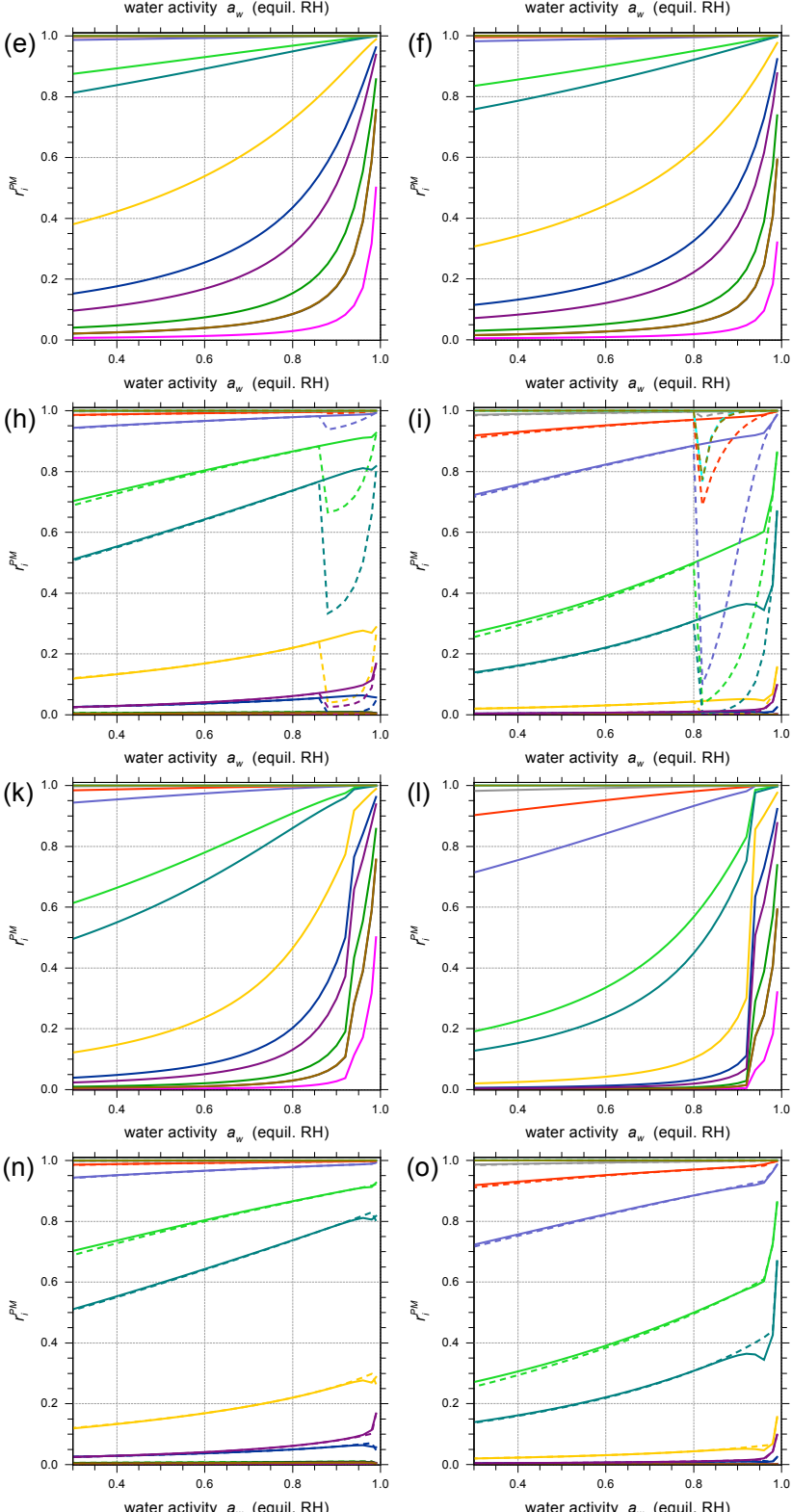
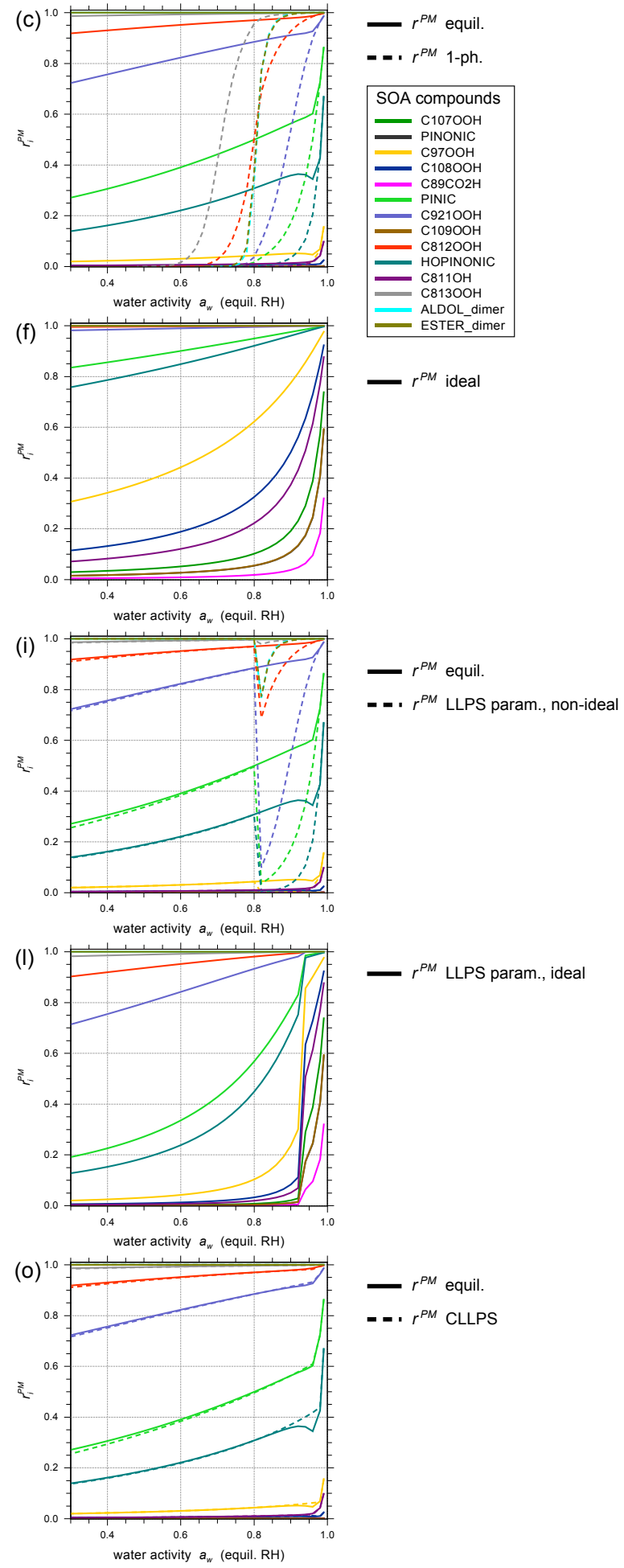

- $r^{P M}$ LLPS param., ideal

Fig. 6. PM phase fractions $\left(r^{\mathrm{PM}}\right)$ of the organic system components as a function of RH at $298 \mathrm{~K}$. Comparison of the different modeling cases with the benchmark (equil.) case for predicted partitioning at three distinct SOA loading levels (see Fig. 5). The RH-dependent partitioning of SVOCs is emphasized in these diagrams. LVOCs partition mostly to the PM $\left(r^{\mathrm{PM}}>0.99\right)$, IVOCs almost entirely to the gas phase $(r \mathrm{PM} \approx 0.0)$, showing little variation with respect to changes in RH and SOA loading. Phase separation leads to a discontinuity in the $r$ PM curves (kinks). 

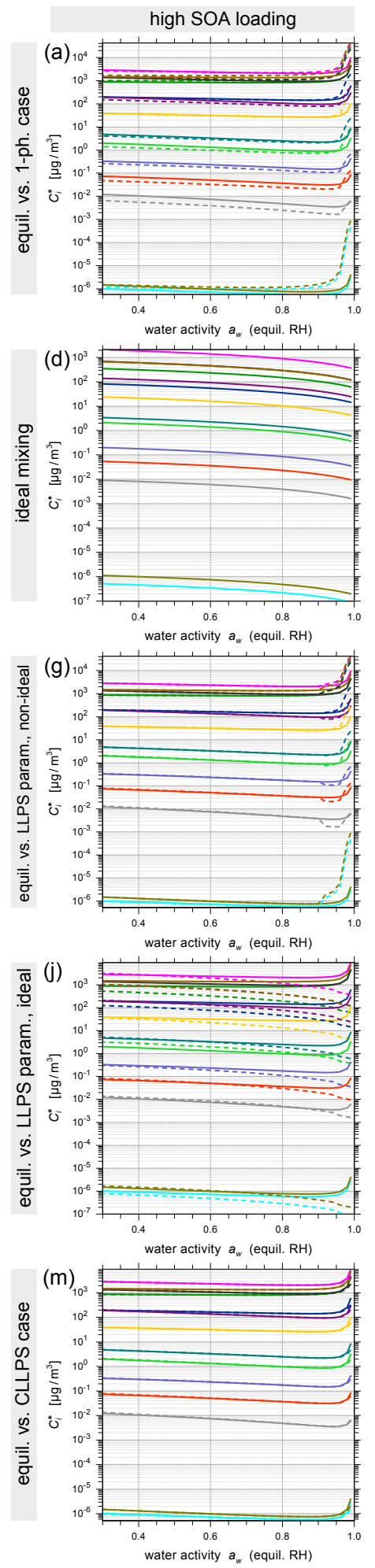
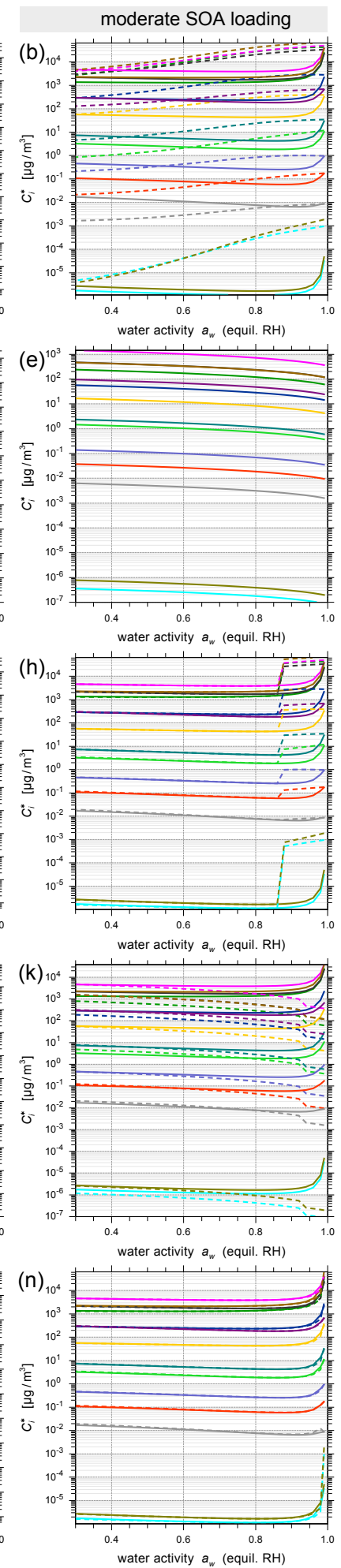
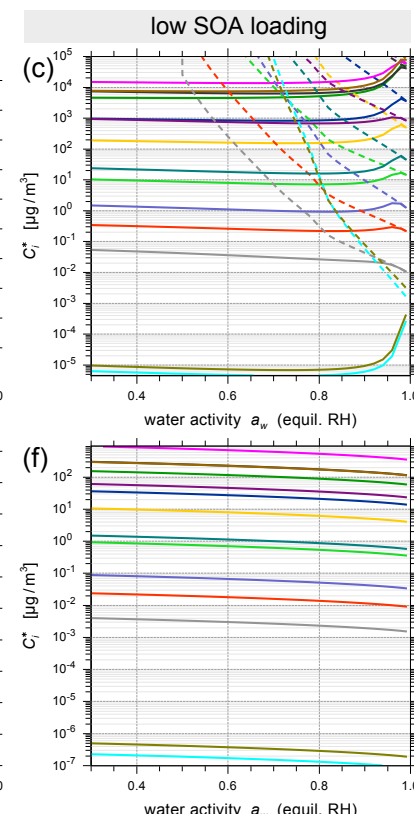

water activity $a_{w}$ (equil. $\left.\mathrm{RH}\right)$
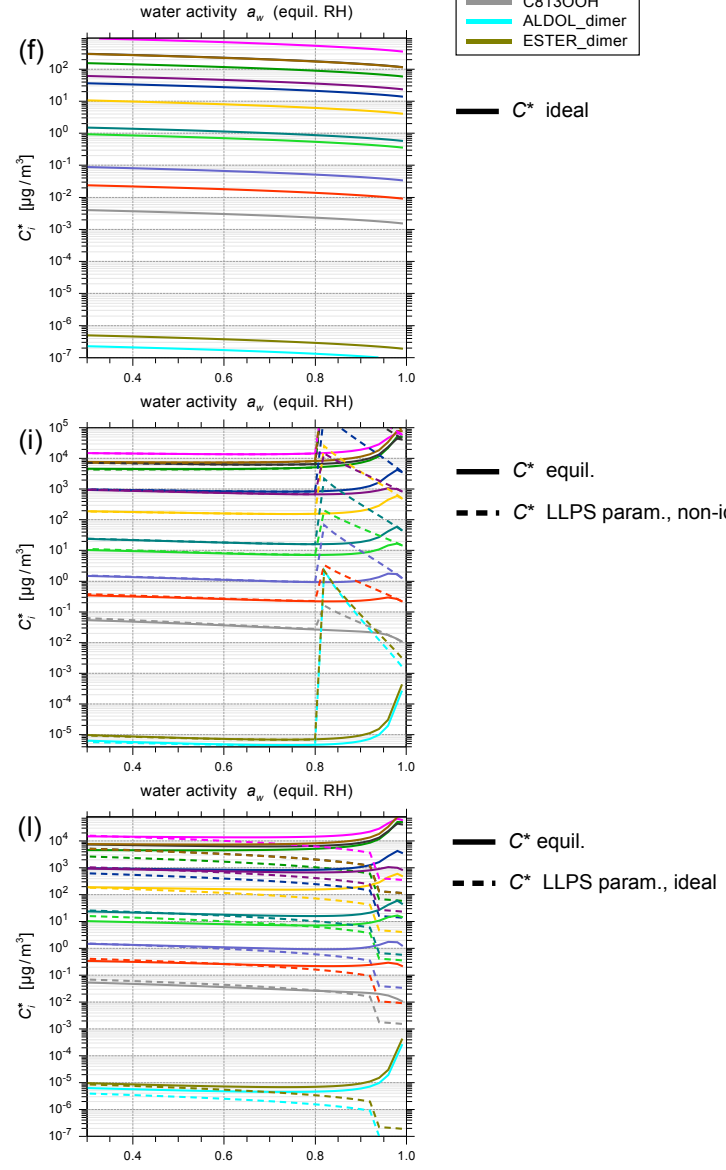

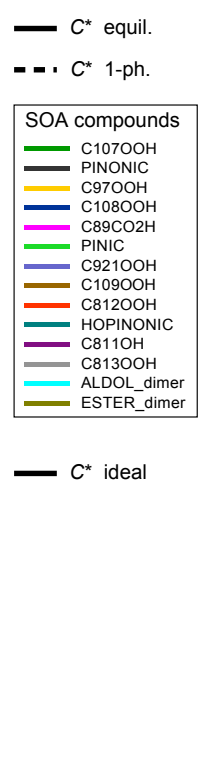

- $C^{*}$ equil.

- - . $C^{*}$ LLPS param., non-ideal
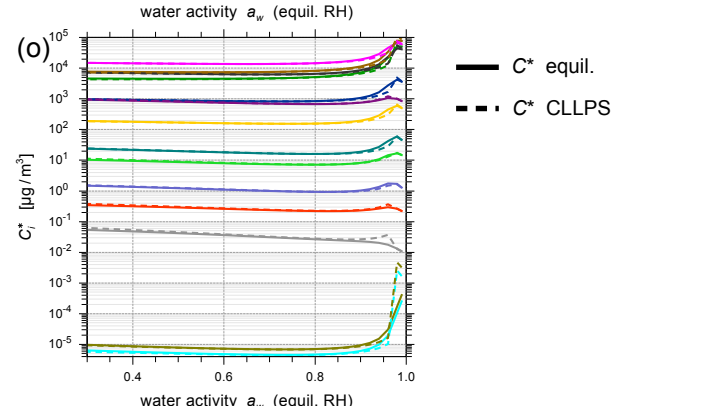

Fig. 7. Effective saturation concentrations, $C^{*}$ (Eq. 5), of the organic system components as a function of RH at $298 \mathrm{~K}$. Comparison of the different modeling cases with the benchmark (equil.) case for predicted partitioning at three distinct SOA loading levels (see Fig. 5). The effect of a high PM water content at high $\mathrm{RH}$ on the $C^{*}$ values is especially prominent for less hydrophilic (low O:C) components, e.g. PINONIC and the dimers. 
solutions containing electrolytes and organics that cannot be ignored.

\subsubsection{LLPS onset parametrization cases}

Total PM mass concentrations predicted by the LLPS param., non-ideal case, shown in the middle row of Fig. 5, agree very well with the equil. case in the RH range where both models predict two liquid phases. This is not surprising, as the equil. case also predicts nearly complete organic/electrolyte LLPS in the RH range where the parameterization of Bertram et al. (2011) predicts phase separation. Thus, since both cases use AIOMFAC to compute non-ideality, this agreement was expected for the $\alpha$-pinene system. LLPS are predicted to be present at RH $\leq 90 \%, \leq 86 \%$, and $\leq 80 \%$, for high, moderate, and low SOA loading levels, respectively, as indicated in Fig. 5d-f. In the RH range higher than the parameterized LLPS onset, the LLPS param., non-ideal case is identical with the forced 1-ph. case. Hence, especially at moderate and low SOA loading, deviations from the equil. case are significant in the predicted one-phase range. These deviations are also clearly visible in Fig. 6g-i, responsible for the discontinuity ("jump") of the dashed $r_{j}^{\mathrm{PM}}$ curves at the predicted LLPS onset RH. Therefore, whether the LLPS param., nonideal case is an accurate model for the real system behavior depends on two main points: (1) whether the parameterized LLPS onset RH is accurate and (2) whether the assumption of a complete organic/electrolyte LLPS is justified. Related to point (1) it should be noted that we use the average organic $\mathrm{O}: \mathrm{C}$ ratio of the $\mathrm{PM}$ phase with the parameterization of Bertram et al. (2011) to predict the LLPS onset RH, however, the actual LLPS onset might be triggered by the lowest-O:C organics present in the solution and may not necessarily be captured well by using the average O:C. The validity of point (2) is related to the average organic $\mathrm{O}: \mathrm{C}$ in the solution, and may become an issue at higher O:C and lower inorganic-toorganic ratios (Song et al., 2012).

Assuming ideal mixing in the two coexisting liquid phases separately leads to better predictions than assuming overall ideal mixing (one phase), especially towards lower RH. Using the parameterization of Bertram et al. (2011), LLPS is predicted to be the stable state at $\mathrm{RH} \leq 94 \%, \leq 92 \%$, and $\leq 92 \%$, for high, moderate, and low SOA loading levels, respectively. Thus, in the LLPS param., ideal case, the onset of LLPS is predicted to occur at significantly higher RH than in the LLPS param., non-ideal case. The dotted curves in Fig. 5d-f show good agreement with the equil. case in terms of total PM mass at $\mathrm{RH}<60 \%$ for moderate and lower loading. However, at higher SOA loading or at higher RH both the total and the organic PM mass are substantially overpredicted. The LLPS param., ideal case performs better at lower loading levels because of the higher average $\mathrm{O}: \mathrm{C}$ in the PM at lower loadings (see Fig. 3), which means that the real system also deviates less from ideal mixing (organics of higher O:C are more hydrophilic and cause less deviation from ideality when mixing with water). At lower RH, assuming ideal mixing in the organic phase becomes more accurate because of the lower water mole fraction and because in this system different organic compounds are similar enough not to cause large deviations from ideal mixing. Furthermore, the total PM mass concentration is also predicted quite well at lower RH, because water activity in binary aqueous ammonium sulfate solutions is well described by Raoult's law (Zuend et al., 2008), and therefore the aqueous electrolyte phase does not lead to large deviations. However, this is not generally the case and an inorganic phase with other electrolytes, such as $\mathrm{NaCl}$, will exhibit large devations from ideal mixing (Zuend et al., 2008). In addition to the shortcomings of the LLPS param., ideal case at high loading and high RH, the same two main points mentioned above regarding the accuracy of LLPS onset prediction and validity of complete organic/electrolyte separation apply.

\subsubsection{CLLPS case}

The CLLPS case is analogous to the LLPS param., non-ideal case in terms of the use of AIOMFAC activity coefficients and will produce the same gas-particle partitioning results when both modeling cases agree on the PM phase state. However, the important difference between the two cases concerns the way a LLPS is predicted. In the CLLPS case, phase separation is predicted to occur at $\mathrm{RH} \leq 99 \%, \leq 98 \%$, and $\leq 96 \%$, for high, moderate, and low SOA loading levels, respectively, as indictated by the arrows in Fig. $5 \mathrm{~g}$-i. Since this simplified approach predicts LLPS onset at comparably high $\mathrm{RH}$ as the equil. case, the agreement in terms of predicted total and organic PM mass concentrations is excellent. Panels (m), (n), and (o) of Fig. 6 reveal that the agreement is also very good regarding individual compound partitioning. The two points regarding the accuracy of LLPS onset prediction and validity of assuming complete organic/electrolyte separation apply to the CLLPS case as well. However, in the CLLPS case the validity of these assumptions is somewhat less critical, because the use of a Gibbs energy-based argument about a one-phase or a two-phase PM is more adaptive. For example, assume that in reality there is a LLPS present in the condensed phase, but incomplete in terms of organic/electrolyte separation: at the overall composition where CLLPS predicts (complete) phase separation, at least the necessary condition will be fulfilled that a complete phase separation has lower Gibbs energy than the corresponding one-phase solution. As mentioned in Sect. 2.4, this means that the CLLPS case will always predict LLPS at RH equal or lower compared to the equil. case, but when a LLPS is predicted, it is safe to assume that a LLPS is actually present and important to consider. Such a conclusion cannot be drawn for the LLPS param., non-ideal case, because in that case the LLPS prediction is not based on a Gibbs energy argument. Since in gas-particle systems like the one in this study, forcing a one-phase PM mixture at relative humidities below 
actual phase separation onset quickly leads to a steep increase in total Gibbs energy, the CLLPS typically predicts LLPS relatively close to the equil. case (in terms of RH). Therefore, with the use of a model like AIOMFAC, which can be used consistently for organic-inorganic one-phase and two-phase mixtures, the CLLPS approach has a clear advantage over the LLPS param., non-ideal case. Note that in contrast to the CLLPS approach, only a method with parameterized LLPS can be used when ideal mixing is assumed in the phase-separated state, as in the LLPS param., ideal case. With the CLLPS approach and ideal mixing, the one-phase state would always result as the stable state.

\subsection{Computational aspects}

Table 2 shows a comparison of the computational costs and expected levels of accuracy associated with the different gasparticle partitioning calculation cases. The computational costs arise from the iterative solution of the system of nonlinear equations for gas-particle equilibrium and, within these iterations, the costs for the calculations of non-ideal mixing and potential phase separation in the particle phase.

While the benchmark equil. case achieves the highest level of accuracy, it requires also the largest computational efforts. Hence, there is a trade-off between computational costs and accuracy that needs to be considered for large-scale model implementations. According to the results presented for the $\alpha$-pinene system and the computation times from Table 2 , the computationally optimal approach when using AIOMFAC is to implement the CLLPS method. Neglecting nonideality is not recommended for the reasons discussed above (Sect. 4.3.1), despite the fact that it would be the fastest option. If the use of other activity coefficient models is preferred, e.g. a different model for the aqueous electrolyte phase than for the aqueous organic phase, using the LLPS param., non-ideal approach with different models would be an alternative. However, the use of different activity coefficient models might pose problems regarding thermodynamic consistency in the stable one-phase region at higher RH.

An important aspect concerns the scaling of the computational costs with the number of system components. Computational costs of the equil. case scale super-linearly with the number of components due to the dimensional dependency of a reliable multidimensional LLPS computation (Zuend et al., 2010). In all other cases, computational costs scale approximately linearly with the number of components when a reasonable initial guess for $r_{j}^{\mathrm{PM}}$ is used. The cases involving calculations of activity coefficients with AIOMFAC are not only slower than the ideal case due to the additional computational costs of the AIOMFAC model - solving reliably the system of nonlinear equations describing gas-particle equilibration is also much more demanding (more iterations) owing to additional nonlinear feedback attributed to the non-ideal PM phase behavior (incl. potential LLPS).
Furthermore, the compositional discontinuity occurring at the onset of LLPS has to be considered in the numerical algorithm used, since otherwise the solver for the system of nonlinear equations could fail to converge (efficient numerical algorithms usually require the functions to be mathematically smooth). This can happen because the simplified LLPS cases use a dynamic definition of whether a two-phase state should be stable or not, depending on the overall PM composition at a certain iteration step. Therefore, in the compositional vicinity of phase separation, the parameterization could oscillate between predicting a two-phase and a one-phase state, which in turn affects the trial-composition in the next iterative step and the solver might fail to converge. This numerical issue can be resolved by temporarily fixing the phase state to a twophase state, when a previous equilibrium one-phase state calculation turned out to be unstable at the given RH and overall composition.

The equil. case calculation mode is the method of choice for accurate offline (box model) computations, where high computational costs are acceptable. This mode allows the most detailed predictions of PM phase compositions and provides necessary information on whether assuming a complete organic/electrolyte phase separation is a good approximation for a given aerosol system.

\section{Implications for atmospheric modeling}

Regional and global atmospheric chemical transport models (CTM) and chemistry-climate models currently rely heavily on simplified schemes to represent gas-particle partitioning to aerosols and cloud droplets. Some of the large-scale models assume internally mixed fine-mode aerosols and reversible equilibrium partitioning of SOA species to an organic phase decoupled from an aqueous electrolyte phase, with predefined and RH-independent empirical partitioning coefficients in a pseudo-ideal manner (e.g. Chung and Seinfeld, 2002; Henze and Seinfeld, 2006; Hoyle et al., 2007, 2009; Pye and Seinfeld, 2010; Kelly et al., 2010; Foley et al., 2010) or adopt an internally mixed, yet phase-separated hydrophobic-hydrophilic approach (e.g. Pun et al., 2002; Griffin et al., 2003; Chen et al., 2006). The results of this study give some theoretically sound justification for the simplifications made in CTMs to use completely phase separated aqueous organic/electrolyte phases - at least under certain mixing conditions (lower $\mathrm{RH}$, lower O:C ratio of organic mixture). However, none of the current CTMs is able to represent internal mixing of organic and inorganic species in a single phase (at high $\mathrm{RH}$ ) and composition-dependent liquid-liquid phase separation in a thermodynamically correct manner. The results of this study enable an educated selection of simplified partitioning schemes based on considerations of thermodynamic consistency, computational efficiency, and required accuracy. This will help to improve the currently limited representation of SOA partitioning as 
Table 2. Comparison of computational costs and accuracy of the different modeling approaches for organic-inorganic gas-particle partitioning (16-component system).

\begin{tabular}{|c|c|c|}
\hline Modeling case & Computational costs (time) $)^{\mathrm{a}}$ & Accuracy ${ }^{b}$ \\
\hline equil. (benchmark) & very high (16000) & very high (benchmark) \\
\hline 1-ph. (non-ideal) & low (6) & low \\
\hline ideal mixing & very low (1) & low \\
\hline LLPS param., non-ideal & moderate (100) & low - high $^{c}$ \\
\hline LLPS param., ideal & low (3) & low - moderate ${ }^{c}$ \\
\hline CLLPS & moderate (100) & high \\
\hline
\end{tabular}

\footnotetext{
a An approximate computation time for the (high precision) solution of the 16-component system as a normalized multiple of the ideal mixing case time is given in parenthesis. On average, a single gas-particle partitioning calculation for the ideal case takes $\sim 0.01 \mathrm{~s}$ on a current workstation (single thread, Intel(R) Core(TM) i7, 3 GHz CPU).

b Accuracy of a modeling case is here judged relative to the equil. case. It is assumed that the equil. case provides the best estimate for the physically "true" solution of the gas-particle partitioning problem, since, in comparison to the simplified cases, the equil. case is least affected by additional assumptions and constraints. However, deviations from the actual solution may still be significant.

${ }^{\mathrm{c}}$ As discussed in the text, these cases may perform well under certain loading and RH conditions, yet can lead to large deviations typically at higher RH.
}

a function of loading and relative humidity. Changes of temperature most prominently affect gas-particle partitioning via the exponential dependency of vapor pressures on temperature. Thus, shifting the range of saturation concentrations where semivolatile partitioning is important. Therefore, the conclusions about the importance of non-ideality and LLPS remain very likely valid over the entire temperature range in the troposphere, at least where particles exist as liquid solutions.

While the quantitative results of this modeling case study are based on a predicted mixture of $\alpha$-pinene SOA and ammonium sulfate, many of the results can be generalized in a qualitative manner. The highly successful group-contribution concept of the AIOMFAC model suggests that the types and relative abundances of functional groups are more important to accurately predict activity coefficients than the exact molecular structure of different compounds (Zuend et al., 2011). Hence, this generalizes the results obtained from the $\alpha$-pinene SOA compounds used to at least the enormous variety of structural isomers. Moreover, the $\mathrm{O}: \mathrm{C}$ ratio is a good first-order proxy for hydrophilicity and hygroscopicity of organic compounds (e.g. Jimenez et al., 2009; Zuend et al., 2010; Massoli et al., 2010; Duplissy et al., 2011; Donahue et al., 2011) and related to that, the expected degree of nonideality due to organic $\leftrightarrow$ inorganic interactions in aqueous mixtures. The average O:C ratio of the SOA components is here $\sim 0.5$, leading to a phase separation up to very high $\mathrm{RH}$. This will also be the case for many other SOA mixtures in the presence of aqueous inorganic ions, when the average O:C ratio is below $\sim 0.7$, as has been found experimentally (Smith et al., 2011; Bertram et al., 2011; Song et al., 2012) and from thermodynamic calculations (Zuend et al., 2010; Song et al., 2012). This means that for simplified gasparticle partitioning schemes in CTMs, assuming a complete organic/electrolyte phase separation in aerosols is a good ap- proximation at $\mathrm{O}: \mathrm{C}<0.7$ when a LLPS is the stable state. Thus, the use of the CLLPS or the LLPS param., non-ideal modeling approach is justified. For $\mathrm{O}: \mathrm{C}<0.5$, assuming a complete organic/electrolyte phase separation over the entire RH range is very likely a valid simplification, that will further speed-up computations. In such cases it will be possible to employ simpler yet computationally more efficient activity coefficient models and empirical mixing rules that cannot deal with organic-inorganic interactions, e.g. ISORROPIA 2 (Fountoukis and Nenes, 2007), multicomponent Taylor expansion method (MTEM) (Zaveri et al., 2005), or Partial Derivative Fitted Taylor Expansion (PD-FiTE) (Topping et al., 2009) for the aqueous electrolyte phase and CPWilson.1 (Chang-Pankow-Wilson.1) (Chang and Pankow, 2010) or organic PD-FiTE (Topping et al., 2012) for the aqueous organic phase.

SOA mixtures with an average $\mathrm{O}: \mathrm{C}>0.7$, may not exhibit phase separation in the presence of dissolved ammonium sulfate even at lower RH (Bertram et al., 2011; Song et al., 2012). However, such SOA mixtures show considerable nonideal mixing and might phase-separate in the presence of other electrolytes, such as $\mathrm{NaCl}$ or $\mathrm{HCl}$. The accurate calculation of the gas-particle partitioning of a mixed organicelectrolyte PM phase requires a thermodynamic model like AIOMFAC, capable of dealing with concentrated mixtures of organic compounds, inorganic salts/acids, and water.

Since chemical reaction equilibria in the aerosol phase depend on the activities of reactants and products, activity coefficient models are also required to improve aqueous phase ("cloud processing") and organic phase chemical reaction schemes. 


\section{Conclusions}

A combination of a gas-phase chemical mechanism, a detailed group-contribution vapor pressure model and a group-contribution activity coefficient model, MCMEVAPORATION-AIOMFAC, has been applied in this study to a realistic organic-inorganic gas-aerosol system. 14 organic species represent semivolatile SOA from $\alpha$-pinene ozonolysis, and ammonium sulfate represents a typical electrolyte found in aqueous aerosols. Gas-particle partitioning calculations with full consideration of non-ideality and potential LLPS have been performed for atmospherically relevant aerosol loading levels and the humidity range from $30 \%$ to $99 \% \mathrm{RH}$. The modeling results allow the following important conclusions:

- The MCM-EVAPORATION-AIOMFAC model is able to accurately reproduce $\alpha$-pinene SOA mass yields from aerosol chamber studies with minimal tuning (one dimer formation parameter).

- The modeling results suggest that ignoring non-ideality by assuming ideal mixing (activity coefficients of unity) in salt-free "organics + water" mixtures, may lead to only small deviations at lower RH (40\% RH in the studied case). However, assuming ideality at higher RH ( $>60 \%$ ), will very likely lead to significant overprediction of SOA mass and total PM mass. This is clearly the case when the actual organic mixture is only moderately hygroscopic, i.e. typically the case for organic mixtures of lower O:C ratios.

- Presence of dissolved inorganic ions (ammonium sulfate) mixed with SOA (as typically the case in the troposphere) make the consideration of non-ideal mixing absolutely necessary for accurate results. Assuming ideal mixing in organic-inorganic particles leads to highly overpredicted organic PM mass (up to $>200 \%$ at $95 \%$ $\mathrm{RH})$.

- Based on the computational results for the aqueous $\alpha$ pinene + ammonium sulfate SOA system and the groupcontribution concept of our model, it is highly probable that SOA of moderate or lower average O:C ratio will cause LLPS in the presence of aqueous inorganic ions. Given the abundance of organic aerosol of moderate or lower average $\mathrm{O}: \mathrm{C}$ in the troposphere (e.g. Aiken et al., 2008; $\mathrm{Ng}$ et al., 2010), it is reasonable to assume that such phase separations are a prevalent feature of atmospheric aerosols over a wide range of $\mathrm{RH}$, aerosol loading, and temperature.

- If non-ideality is considered (highly recommended), LLPS needs to be considered as well. Ignoring a LLPS by forcing a single non-ideal phase, can lead to vastly incorrect partitioning predictions.
- Water soluble organic compounds (WSOC) will not necessarily partition to the "aqueous phase" in ambient aerosols; rather, when an aqueous organic-rich phase is present with moderate average $\mathrm{O}: \mathrm{C}$, WSOC will likely partition preferentially to the organic phase, because salting-out effects at $\mathrm{RH}<90 \%$ prevent partitioning to the aqueous electrolyte-rich phase.

- For O:C ratios lower than $\sim 0.5$, the results from the $\alpha$ pinene SOA system calculations suggest that it is justified to assume a complete organic/electrolyte phase separation up to high RH. This allows for simplified gasparticle partitioning models, e.g. the evaluated CLLPS approach.

- Partitioning schemes based on complete organic/electrolyte phase separation, where applicable (see point above), allow accurate and much more computationally efficient methods than a demanding thermodynamic computation with full equilibration of all components between all coexisting phases.

- For aerosol compositions in which the assumption of complete organic/electrolyte LLPS is justified, the CLLPS case shows that total PM as well as individual compound partitioning are reproduced very well.

The application of the AIOMFAC model with the new implementation of hydroperoxide functionalities is shown to be useful for both thermodynamic benchmark computations with Gibbs energy minimization as well as in simplified partitioning schemes. The efficiency of implementing such schemes in 3-D models using AIOMFAC for activity coefficient calculations has not been tested to date and is the subject of future work.

\section{Appendix A}

\section{New functional groups in AIOMFAC}

In Sect. 2.2.3 we discuss the necessity for the implementation of peroxide functionalities in AIOMFAC to describe several of the $\alpha$-pinene oxidation products. The usual approach of adding new functionalities to AIOMFAC using experimental data and fitting of interaction parameters (Zuend et al., 2008, 2011) is not applicable for peroxide, organonitrate, and peroxy acyl nitrate functional groups, due to the lack of experimental thermodynamic equilibrium data. Compernolle et al. (2009) adopt a different approach to fit UNIFAC model parameters for these functional groups: they generate activity coefficient data using the SPARC (Sparc Performs Automated Reasoning in Chemistry) model (Carreira et al., 1994; Hilal et al., 2004), available online at http://ibmlc2.chem.uga.edu/sparc/. Required model parameters are then fitted to the generated data sets. Since the shortrange interaction contributions in AIOMFAC are calculated 
Table A1. List of new AIOMFAC main groups and corresponding subgroups.

\begin{tabular}{|c|c|c|}
\hline Group name & Main group* & Subgroup \\
\hline Organonitrate & $\mathrm{CH}_{\mathrm{n}} \mathrm{ONO}_{2}$ & $\begin{array}{l}\mathrm{CH}_{2} \mathrm{ONO}_{2} \\
\mathrm{CHONO}_{2} \\
\mathrm{CONO}_{2}\end{array}$ \\
\hline Hydroperoxide & $\mathrm{CH}_{\mathrm{n}} \mathrm{OOH}[$ perox $]$ & $\begin{array}{l}\mathrm{CH}_{2} \mathrm{OOH}[\text { perox }] \\
\mathrm{CHOOH}[\text { perox }] \\
\mathrm{COOH}[\text { perox] }\end{array}$ \\
\hline Peroxyacid & $\mathrm{C}(=\mathrm{O}) \mathrm{OOH}[$ perox $]$ & $\mathrm{C}(=\mathrm{O}) \mathrm{OOH}[$ perox $]$ \\
\hline Peroxide & $\mathrm{CH}_{\mathrm{n}} \mathrm{OOCH}_{\mathrm{m}}[$ perox $]$ & $\begin{array}{l}\mathrm{CH}_{3} \mathrm{OOCH}_{3} \text { [perox] } \\
\mathrm{CH}_{3} \mathrm{OOCH}_{2} \text { [perox] } \\
\mathrm{CH}_{3} \mathrm{OOCH} \text { [perox] } \\
\mathrm{CH}_{3} \mathrm{OOC}[\text { perox] } \\
\mathrm{CH}_{2} \mathrm{OOCH} \mathrm{H}_{2} \text { [perox] } \\
\mathrm{CH}_{2} \mathrm{OOCH}[\text { perox] } \\
\mathrm{CH}_{2} \mathrm{OOC}[\text { perox] } \\
\mathrm{CHOOCH}[\text { perox] } \\
\mathrm{CHOOC}[\text { perox] } \\
\mathrm{COOC}[\text { perox] }\end{array}$ \\
\hline Peroxy acyl nitrate & $\mathrm{C}(=\mathrm{O}) \mathrm{OONO}_{2}[$ perox $]$ & $\mathrm{C}(=\mathrm{O}) \mathrm{OONO}_{2}[$ perox $]$ \\
\hline
\end{tabular}

* The label [perox] is added to emphasize the peroxide nature of the $-\mathrm{O}-\mathrm{O}-$ bonds in the groups and to unambiguously distinguish these groups from other AIOMFAC groups, e.g. carboxyl $\mathrm{COOH}$ from hydroperoxide $\mathrm{COOH}[$ perox].

by a UNIFAC model that is compatible with the model version and parameter sets of Compernolle et al. (2009), we adopt their implementation. Table A1 lists the new AIOMFAC main groups and corresponding subgroup names. Relative van der Waals volume and surface area parameters for the new groups are taken from Table 1 of Compernolle et al. (2009) and relevant UNIFAC main group interaction parameters from Tables 5, 6, and 7 of Compernolle et al. (2009).

In Zuend et al. (2011) a functional group polarity series is introduced that allows for constraints on AIOMFAC interaction parameters between organic functional groups and inorganic ions. This polarity series is combined with the idea of an analogy approach (Compernolle et al., 2009) to assign AIOMFAC middle-range interaction parameters to new main groups $\leftrightarrow$ ion interactions based on linear combinations of interaction parameters from already implemented main group-ion pairs. The following substitutions are made:

$$
\begin{aligned}
\mathrm{CH}_{\mathrm{n}} \mathrm{OOH}[\text { perox }] & \approx \mathrm{CH}_{\mathrm{n}} \mathrm{O}+\mathrm{OH} \\
\mathrm{C}(=\mathrm{O}) \mathrm{OOH}[\text { perox }] & \approx \mathrm{COOH} \\
\mathrm{CH}_{\mathrm{n}} \mathrm{OOCH} \text { m }[\text { perox }] & \approx \mathrm{CH}_{\mathrm{n}} \mathrm{O}+\mathrm{CH}_{\mathrm{m}} \mathrm{O}
\end{aligned}
$$

Analogous substitutions for the organonitrate and peroxy acyl nitrate groups are possible as well (Compernolle et al., 2009), but are not realized at this point, because AIOMFAC does not include any other nitrogen-containing groups with associated main group $\leftrightarrow$ ion interaction parameters. Hence, a substitution for those new groups would not help to determine the required interaction parameters with ions. Therefore, the new organonitrate and peroxy acyl nitrate groups will only be available in AIOMFAC for calculations of activity coefficients in electrolyte-free mixtures (UNIFAC-like mode). This may be changed in the future, if a wider set of nitrogen-containing groups is added to the model.

Table A2 lists the new AIOMFAC main group $\leftrightarrow$ ion interaction parameters, which were obtained using known middle-range interaction parameters from the substituted main groups. The table is organized in the same manner as Table 7 of Zuend et al. (2011) and adds the three groups hydroperoxide, peroxyacid, and peroxide to the list of fully implemented AIOMFAC functionalities.

In addition, $\alpha$-pinene oxidation products containing an ester functionality demanded an estimation of the $\mathrm{CCOO} \leftrightarrow \mathrm{NH}_{4}^{+}$interaction, which previously had not been determined (Zuend et al., 2011). In the absence of experimental data, we estimate the AIOMFAC interaction parameter $\mathrm{CCOO} \leftrightarrow \mathrm{NH}_{4}^{+}$based on the functional group polarity series analogy approach, using the ketone group to substitute the ester functionality ( $\mathrm{CCOO} \approx \mathrm{CH}_{\mathrm{n}} \mathrm{CO}$ ). Table 7 of Zuend et al. (2011) reveals that this substitution is a good approximation in most cases where both ketone and ester interactions with ions have been determined. Applying the substitution, the two estimated model parameters are: $b_{\mathrm{CCOO}, \mathrm{NH}_{4}^{+}}^{(1)}=$ $9.37140 \times 10^{-2} \mathrm{~kg} \mathrm{~mol}^{-1}$ and $b_{\mathrm{CCOO}, \mathrm{NH}_{4}^{+}}^{(2)}=5.16922 \times 10^{-2}$ $\mathrm{kg} \mathrm{mol}^{-1}$.

\section{Appendix B}

\section{Computed phase diagram}

Figure B1 shows a 2-dimensional representation, water activity (equil. RH) vs. water-free composition, of the liquid PM composition phase diagram for the 16-component system, $\alpha$-pinene SOA products + water + ammonium sulfate (AS), at $298 \mathrm{~K}$. The phase diagram was computed with the method of Zuend et al. (2010), using AIOMFAC activities to determine the global Gibbs energy minimum and the potential for a liquid-liquid phase separation at each initial composition point. Fixed molar ratios between the different organic compounds in the overall PM system were used in the computation. These molar ratios were determined based on the data from the equil. case gas-particle partitioning calculation at $T=298 \mathrm{~K}, 80 \% \mathrm{RH}$, moderate SOA loading, and $\lambda=10 \%$. Assuming fixed molar ratios of organic compound abundances is supported by Fig. $4 \mathrm{~b}$, which shows that the relative mass conc. of PM-phase organic species does change only slightly over the RH range considered. Such fixed molar ratios of the organic PM fraction allow expressing the water-free "dry" (initial) one-phase system composition on the $\mathrm{x}$-axis in terms of $\mathrm{mf}_{d}(\mathrm{AS})=\operatorname{mass}(\mathrm{AS}) /(\operatorname{mass}(\mathrm{AS})+$ mass(PM organics)), i.e. a representation of the overall organic:AS ratio in the PM. In addition, AS is allowed to become metastable in solution, i.e. supersaturated with respect to the thermodynamically stable solid state. 


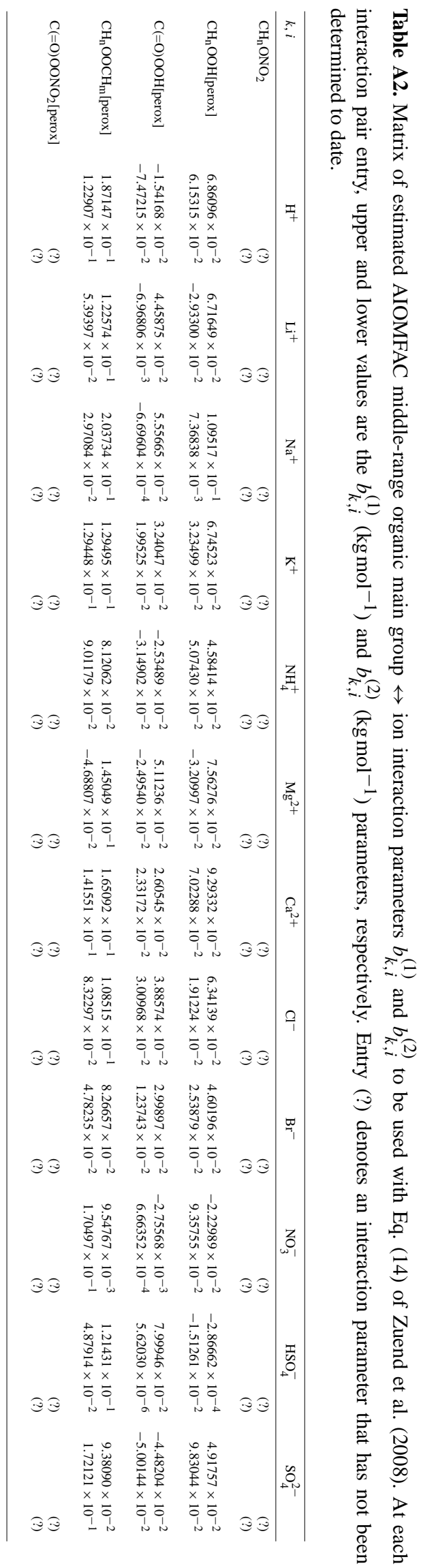

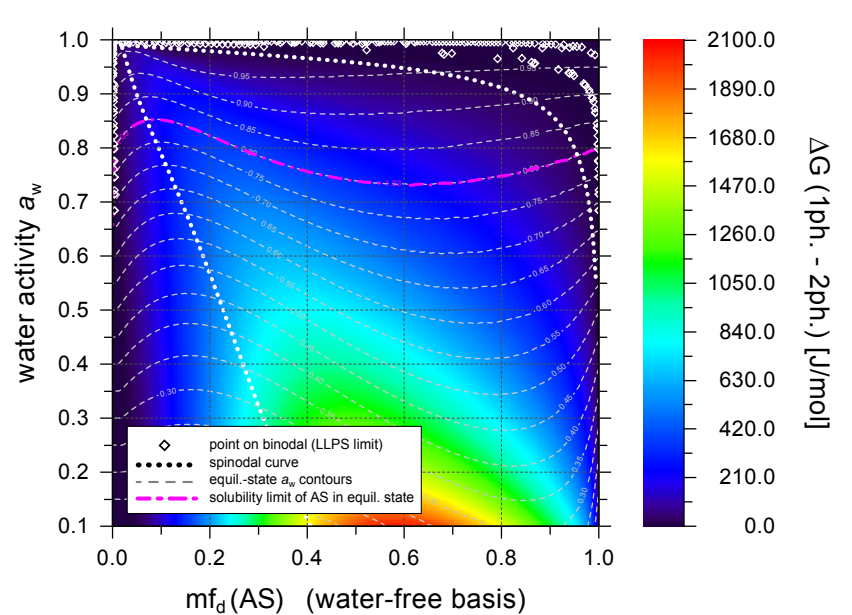

Fig. B1. Computed phase diagram of the 16-component system " $\alpha$ pinene SOA products + water + ammonium sulfate (AS)" in the liquid PM, based on the method of Zuend et al. (2010). Conditions: $T=298 \mathrm{~K}$, fixed molar ratios of relative organic compound abundances as derived from equil. case gas-particle partitioning calculation at $80 \% \mathrm{RH}$, moderate SOA loading, and $\lambda=10 \%$. Shown is a point-by-point mapping of the 16-dimensional phase composition space to a 2-D representation: water activity vs. mass fraction of AS in the "dry" (on water-free basis) mixture of organics $+\mathrm{AS}, \mathrm{mf}_{d}(\mathrm{AS})$. The color-axis shows the Gibbs energy difference between a forced one-phase (non-ideal) calculation and the equilibrium state calculation, showing LLPS up to high water activity, i.e. high RH.

The limits of intrinsic stability of a liquid one-phase system are shown by the spinodal curves (dotted, white), calculated based on a modification of the method by Zuend et al. (2010), generalized to systems with any number of components. The composition space enclosed by the spinodals is thermodynamically unstable and LLPS is predicted to occur spontaneously (spinodal decomposition). The Gibbs energy difference (color-axis) between a one-phase state and the equilibrium state (one- or two-phase state), as well as the calculated points on the binodals (coexistence curves, LLPS limit), show that LLPS is predicted to exist up to high RH. This is in agreement with the results from the equil. case gas-particle partitioning calculations. In contrast to many binary and ternay phase diagrams, this 16-component system has more than one set of binodal curves, as visible at higher $\operatorname{mf}_{d}(\mathrm{AS})$ and high $a_{\mathrm{w}}$ in Fig. B1. These binodal curves, and associated miscibility gaps, seem to overlap, yet this is a consequence of the chosen 2-dimensional mapping of the actual 16-dimensional composition space. Comparison to the low SOA loading case shown in Fig. 4c, corresponding to $\operatorname{mf}_{d}(\mathrm{AS}) \approx 0.766$, indicates that one of the binodals is associated with the incomplete LLPS at high RH, where only the lowest-O:C components partition to an organic-rich phase $\beta$.

The solubility limit of AS is shown by the pink, dashdotted curve, calculated as the molal ion activity product at saturation, with the solubility in the binary aqueous 
ammonium sulfate system as reference point. Due to the existence of a nearly complete LLPS over most of the $\mathrm{mf}_{d}(\mathrm{AS})$ range, in the LLPS region, this solubility limit is parallel to the water activity contours of the corresponding equilibrium state (Zuend et al., 2010).

Acknowledgements. We would like to thank Marie Camredon and John E. Shilling for providing aerosol chamber data and Claudia Marcolli for helpful comments and discussions. This work was supported by the US National Science Foundation grant AGS-1057183. This work was also supported by the US Electric Power Research Institute.

Edited by: A. Nenes

\section{References}

Anttila, T., Kiendler-Scharr, A., Mentel, T., and Tillmann, R.: Size dependent partitioning of organic material: evidence for the formation of organic coatings on aqueous aerosols, J. Atmos. Chem., 57, 215-237, doi:10.1007/s10874-007-9067-9, 2007.

Barley, M. H. and McFiggans, G.: The critical assessment of vapour pressure estimation methods for use in modelling the formation of atmospheric organic aerosol, Atmos. Chem. Phys., 10, 749767, doi:10.5194/acp-10-749-2010, 2010.

Bertram, A. K., Martin, S. T., Hanna, S. J., Smith, M. L., Bodsworth, A., Chen, Q., Kuwata, M., Liu, A., You, Y., and Zorn, S. R.: Predicting the relative humidities of liquid-liquid phase separation, efflorescence, and deliquescence of mixed particles of ammonium sulfate, organic material, and water using the organic-to-sulfate mass ratio of the particle and the oxygen-tocarbon elemental ratio of the organic component, Atmos. Chem. Phys., 11, 10995-11006, doi:10.5194/acp-11-10995-2011, 2011.

Booth, A. M., Barley, M. H., Topping, D. O., McFiggans, G., Garforth, A., and Percival, C. J.: Solid state and sub-cooled liquid vapour pressures of substituted dicarboxylic acids using Knudsen Effusion Mass Spectrometry (KEMS) and Differential Scanning Calorimetry, Atmos. Chem. Phys., 10, 4879-4892, doi:10.5194/acp-10-4879-2010, 2010.

Camredon, M., Hamilton, J. F., Alam, M. S., Wyche, K. P., Carr, T., White, I. R., Monks, P. S., Rickard, A. R., and Bloss, W. J.: Distribution of gaseous and particulate organic composition during dark $\alpha$-pinene ozonolysis, Atmos. Chem. Phys., 10, 2893-2917, doi:10.5194/acp-10-2893-2010, 2010.

Cappa, C. D. and Wilson, K. R.: Evolution of organic aerosol mass spectra upon heating: implications for OA phase and partitioning behavior, Atmos. Chem. Phys., 11, 1895-1911, doi:10.5194/acp11-1895-2011, 2011.

Cappa, C. D., Lovejoy, E. R., and Ravishankara, A. R.: Evidence for liquid-like and nonideal behavior of a mixture of organic aerosol components, P. Natl. Acad. Sci. USA, 105, 1868718691, doi:10.1073/pnas.0802144105, 2008.

Carreira, L. A., Hilal, S., and Karickhoff, S. W.: Estimation of Chemical Reactivity Parameters and Physical Properties of Organic Molecules Using SPARC, chap. 9, Theoretical and Computational Chemistry, Elsevier, 1994.

Chang, E. I. and Pankow, J. F.: Prediction of activity coefficients in liquid aerosol particles containing organic compounds, dissolved inorganic salts, and water - Part 2: Consideration of phase separation effects by an X-UNIFAC model, Atmos. Environ., 40, 6422-6436, doi:10.1016/j.atmosenv.2006.04.031, 2006.

Chang, E. I. and Pankow, J. F.: Organic particulate matter formation at varying relative humidity using surrogate secondary and primary organic compounds with activity corrections in the condensed phase obtained using a method based on the Wilson equation, Atmos. Chem. Phys., 10, 5475-5490, doi:10.5194/acp-105475-2010, 2010.

Chattopadhyay, S. and Ziemann, P. J.: Vapor pressures of substituted and unsubstituted monocarboxylic and dicarboxylic acids measured using an improved thermal desorption particle beam mass spectrometry method, Aerosol Sci. Technol., 39, 10851100, doi:10.1080/02786820500421547, 2005.

Chen, J., Mao, H., Talbot, R. W., and Griffin, R. J.: Application of the CACM and MPMPO modules using the CMAQ model for the eastern United States, J. Geophys. Res., 111, D23S25, doi:10.1029/2006JD007603, 2006.

Chen, Q., Liu, Y., Donahue, N. M., Shilling, J. E., and Martin, S. T.: Particle-Phase Chemistry of Secondary Organic Material: Modeled Compared to Measured O:C and H:C Elemental Ratios Provide Constraints, Environ. Sci. Technol., 45, 4763-4770, doi:10.1021/es104398s, 2011.

Chung, S. H. and Seinfeld, J. H.: Global distribution and climate forcing of carbonaceous aerosols, J. Geophys. Res., 107, 4407, doi:10.1029/2001JD001397, 2002.

Ciobanu, V. G., Marcolli, C., Krieger, U. K., Weers, U., and Peter, T.: Liquid-Liquid Phase Separation in Mixed Organic/Inorganic Aerosol Particles, J. Phys. Chem. A, 113, 10966-10978, doi:10.1021/jp905054d, 2009.

Ciobanu, V. G., Marcolli, C., Krieger, U. K., Zuend, A., and Peter, T.: Efflorescence of ammonium sulfate and coated ammonium sulfate particles: evidence for surface nucleation., J. Phys. Chem. A, 114, 9486-9495, doi:10.1021/jp103541w, 2010.

Clegg, S. L., Seinfeld, J. H., and Brimblecombe, P.: Thermodynamic modelling of aqueous aerosols containing electrolytes and dissolved organic compounds, J. Aerosol. Sci., 32, 713-738, 2001.

Cocker, D. R., Clegg, S. L., Flagan, R. C., and Seinfeld, J. H.: The effect of water on gas-particle partitioning of secondary organic aerosol. Part I: $\alpha$-pinene/ozone system, Atmos. Environ., 35, 6049-6072, 2001.

Compernolle, S., Ceulemans, K., and Müller, J.-F.: Influence of non-ideality on condensation to aerosol, Atmos. Chem. Phys., 9, 1325-1337, doi:10.5194/acp-9-1325-2009, 2009.

Compernolle, S., Ceulemans, K., and Müller, J.-F.: EVAPORATION: a new vapour pressure estimation methodfor organic molecules including non-additivity and intramolecular interactions, Atmos. Chem. Phys., 11, 9431-9450, doi:10.5194/acp-119431-2011, 2011.

Donahue, N. M., Robinson, A. L., Stanier, C. O., and Pandis, S. N.: Coupled Partitioning, Dilution, and Chemical Aging of Semivolatile Organics, Environ. Sci. Technol., 40, 2635-2643, doi:10.1021/es052297c, 2006.

Donahue, N. M., Epstein, S. A., Pandis, S. N., and Robinson, A. L.: A two-dimensional volatility basis set: 1. organic-aerosol mixing thermodynamics, Atmos. Chem. Phys., 11, 3303-3318, doi:10.5194/acp-11-3303-2011, 2011. 
Donahue, N. M., Kroll, J. H., Pandis, S. N., and Robinson, A. L.: A two-dimensional volatility basis set - Part 2: Diagnostics of organic-aerosol evolution, Atmos. Chem. Phys., 12, 615-634, doi:10.5194/acp-12-615-2012, 2012.

Duplissy, J., DeCarlo, P. F., Dommen, J., Alfarra, M. R., Metzger, A., Barmpadimos, I., Prevot, A. S. H., Weingartner, E., Tritscher, T., Gysel, M., Aiken, A. C., Jimenez, J. L., Canagaratna, M. R., Worsnop, D. R., Collins, D. R., Tomlinson, J., and Baltensperger, U.: Relating hygroscopicity and composition of organic aerosol particulate matter, Atmos. Chem. Phys., 11, 11551165, doi:10.5194/acp-11-1155-2011, 2011.

Erdakos, G. B. and Pankow, J. F.: Gas/particle partitioning of neutral and ionizing compounds to single- and multi-phase aerosol particles. 2. Phase separation in liquid particulate matter containing both polar and low-polarity organic compounds, Atmos. Environ., 38, 1005-1013, doi:10.1016/j.atmosenv.2003.10.038, 2004.

Ervens, B., Feingold, G., Frost, G. J., and Kreidenweis, S. M.: A modeling study of aqueous production of dicarboxylic acids: 1. Chemical pathways and speciated organic mass production, J. Geophys. Res.-Atmos., 109, D15205, doi:10.1029/2003JD004387, 2004.

Ervens, B., Turpin, B. J., and Weber, R. J.: Secondary organic aerosol formation in cloud droplets and aqueous particles (aqSOA): a review of laboratory, field and model studies, Atmos. Chem. Phys., 11, 11069-11102, doi:10.5194/acp-1111069-2011, 2011.

Foley, K. M., Roselle, S. J., Appel, K. W., Bhave, P. V., Pleim, J. E., Otte, T. L., Mathur, R., Sarwar, G., Young, J. O., Gilliam, R. C., Nolte, C. G., Kelly, J. T., Gilliland, A. B., and Bash, J. O.: Incremental testing of the Community Multiscale Air Quality (CMAQ) modeling system version 4.7, Geosci. Model Dev., 3, 205-226, doi:10.5194/gmd-3-205-2010, 2010.

Fountoukis, C. and Nenes, A.: ISORROPIA II: a computationally efficient thermodynamic equilibrium model for $\mathrm{K}^{+}$$\mathrm{Ca}^{2+}-\mathrm{Mg}^{2+}-\mathrm{NH}_{4}^{+}-\mathrm{Na}^{+}-\mathrm{SO}_{4}^{2-}-\mathrm{NO}_{3}^{-}-\mathrm{Cl}^{-}-\mathrm{H}_{2} \mathrm{O}$ aerosols, Atmos. Chem. Phys., 7, 4639-4659, doi:10.5194/acp-7-4639-2007, 2007.

Fredenslund, A., Jones, R. L., and Prausnitz, J. M.: GroupContribution Estimation of Activity Coefficients in Nonideal Liquid Mixtures, AIChE J., 21, 1086-1099, 1975.

Frosch, M., Zardini, A. A., Platt, S. M., Müller, L., Reinnig, M.C., Hoffmann, T., and Bilde, M.: Thermodynamic properties and cloud droplet activation of a series of oxo-acids, Atmos. Chem. Phys., 10, 5873-5890, doi:10.5194/acp-10-5873-2010, 2010.

Griffin, R. J., Nguyen, K., Dabdub, D., and Seinfeld, J. H.: A Coupled Hydrophobic-Hydrophilic Model for Predicting Secondary Organic Aerosol Formation, J. Atmos. Chem., 44, 171190, 2003.

Hallquist, M., Wenger, J. C., Baltensperger, U., Rudich, Y., Simpson, D., Claeys, M., Dommen, J., Donahue, N. M., George, C., Goldstein, A. H., Hamilton, J. F., Herrmann, H., Hoffmann, T., Iinuma, Y., Jang, M., Jenkin, M. E., Jimenez, J. L., Kiendler-Scharr, A., Maenhaut, W., McFiggans, G., Mentel, Th. F., Monod, A., Prévôt, A. S. H., Seinfeld, J. H., Surratt, J. D., Szmigielski, R., and Wildt, J.: The formation, properties and impact of secondary organic aerosol: current and emerging issues, Atmos. Chem. Phys., 9, 5155-5236, doi:10.5194/acp-9-51552009, 2009.
Hansen, H. K., Rasmussen, P., Fredenslund, A., Schiller, M., and Gmehling, J.: Vapor-liquid-equilibria by UNIFAC group contribution. 5. Revision and extension, Ind. Eng. Chem. Res., 30, 2352-2355, 1991.

Henze, D. K. and Seinfeld, J. H.: Global secondary organic aerosol from isoprene oxidation, Geophys. Res. Lett., 33, L09812, doi:10.1029/2006GL025976, 2006.

Herrmann, H., Tilgner, A., Barzaghi, P., Majdik, Z., Gligorovski, S., Poulain, L., and Monod, A.: Towards a more detailed description of tropospheric aqueous phase organic chemistry: CAPRAM 3.0, Atmos. Environ., 39, 4351-4363, doi:10.1016/j.atmosenv.2005.02.016, 2005.

Hilal, S. H., Karickhoff, S. W., and Carreira, L. A.: Prediction of the solubility, activity coefficient and liquid/liquid partition coefficient of organic compounds, QSAR Comb. Sci., 23, 709-720, doi:10.1002/qsar.200430866, 2004.

Hoyle, C. R., Berntsen, T., Myhre, G., and Isaksen, I. S. A.: Secondary organic aerosol in the global aerosol - chemical transport model Oslo CTM2, Atmos. Chem. Phys., 7, 5675-5694, doi:10.5194/acp-7-5675-2007, 2007.

Hoyle, C. R., Myhre, G., Berntsen, T. K., and Isaksen, I. S. A.: Anthropogenic influence on SOA and the resulting radiative forcing, Atmos. Chem. Phys., 9, 2715-2728, doi:10.5194/acp-9-27152009, 2009.

Huisman, A. J., Krieger, U. K., Zuend, A., Marcolli, C., and Peter, T.: Vapor pressures of substituted polycarboxylic acids, in preparation, 2012.

Jenkin, M. E.: Modelling the formation and composition of secondary organic aerosol from $\alpha$ - and $\beta$-pinene ozonolysis using MCM v3, Atmos. Chem. Phys., 4, 1741-1757, doi:10.5194/acp4-1741-2004, 2004.

Jenkin, M. E., Saunders, S. M., and Pilling, M. J.: The tropospheric degradation of volatile organic compounds: A protocol for mechanism development, Atmos. Environ., 31, 81-104, doi:10.1016/S1352-2310(96)00105-7, 1997.

Jimenez, J. L., Canagaratna, M. R., Donahue, N. M., Prevot, A. S. H., Zhang, Q., Kroll, J. H., DeCarlo, P. F., Allan, J. D., Coe, H., Ng, N. L., Aiken, A. C., Docherty, K. S., Ulbrich, I. M., Grieshop, A. P., Robinson, A. L., Duplissy, J., Smith, J. D., Wilson, K. R., Lanz, V. A., Hueglin, C., Sun, Y. L., Tian, J., Laaksonen, A., Raatikainen, T., Rautiainen, J., Vaattovaara, P., Ehn, M., Kulmala, M., Tomlinson, J. M., Collins, D. R., Cubison, M. J., Dunlea, E. J., Huffman, J. A., Onasch, T. B., Alfarra, M. R., Williams, P. I., Bower, K., Kondo, Y., Schneider, J., Drewnick, F., Borrmann, S., Weimer, S., Demerjian, K., Salcedo, D., Cottrell, L., Griffin, R., Takami, A., Miyoshi, T., Hatakeyama, S., Shimono, A., Sun, J. Y., Zhang, Y. M., Dzepina, K., Kimmel, J. R., Sueper, D., Jayne, J. T., Herndon, S. C., Trimborn, A. M., Williams, L. R., Wood, E. C., Middlebrook, A. M., Kolb, C. E., Baltensperger, U., and Worsnop, D. R.: Evolution of Organic Aerosols in the Atmosphere, Science, 326, 1525-1529, doi:10.1126/science.1180353, 2009.

Kalberer, M., Paulsen, D., Sax, M., Steinbacher, M., Dommen, J., Prevot, A. S. H., Fisseha, R., Weingartner, E., Frankevich, V., Zenobi, R., and Baltensperger, U.: Identification of Polymers asMajor Components of Atmospheric Organic Aerosols, Science, 303, 1659-1662, 2004.

Kanakidou, M., Seinfeld, J. H., Pandis, S. N., Barnes, I., Dentener, F. J., Facchini, M. C., Van Dingenen, R., Ervens, B., Nenes, A., 
Nielsen, C. J., Swietlicki, E., Putaud, J. P., Balkanski, Y., Fuzzi, S., Horth, J., Moortgat, G. K., Winterhalter, R., Myhre, C. E. L., Tsigaridis, K., Vignati, E., Stephanou, E. G., and Wilson, J.: Organic aerosol and global climate modelling: a review, Atmos. Chem. Phys., 5, 1053-1123, doi:10.5194/acp-5-1053-2005, 2005.

Kelly, J. T., Bhave, P. V., Nolte, C. G., Shankar, U., and Foley, K. M.: Simulating emission and chemical evolution of coarse seasalt particles in the Community Multiscale Air Quality (CMAQ) model, Geosci. Model Dev., 3, 257-273, doi:10.5194/gmd-3257-2010, 2010.

Knopf, D. A., Anthony, L. M., and Bertram, A. K.: Reactive Uptake of $\mathrm{O}_{3}$ by Multicomponent and Multiphase Mixtures Containing Oleic Acid, J. Phys. Chem. A, 109, 5579-5589, 2005.

Koop, T., Bookhold, J., Shiraiwa, M., and Poschl, U.: Glass transition and phase state of organic compounds: dependency on molecular properties and implications for secondary organic aerosols in the atmosphere, Phys. Chem. Chem. Phys., 13, 19238-19255, doi:10.1039/c1cp22617g, 2011.

Kroll, J. H. and Seinfeld, J. H.: Chemistry of secondary organic aerosol: Formation and evolution of low-volatility organics in the atmosphere, Atmos. Environ., 42, 3593-3624, doi:10.1016/j.atmosenv.2008.01.003, 2008.

Kwamena, N.-O. A., Buajarern, J., and Reid, J. P.: Equilibrium Morphology of Mixed Organic/Inorganic/Aqueous Aerosol Droplets: Investigating the Effect of Relative Humidity and Surfactants, J. Phys. Chem. A, 114, 5787-5795, doi:10.1021/jp1003648, 2010.

Lienhard, D. M., Zobrist, B., Zuend, A., Krieger, U. K., and Peter, T.: Experimental evidence for excess entropy discontinuities in glass-forming solutions, J. Chem. Phys., 136, 074515, doi:10.1063/1.3685902, 2012.

Lim, H.-J., Carlton, A. G., and Turpin, B. J.: Isoprene Forms Secondary Organic Aerosol through Cloud Processing: Model Simulations, Environ. Sci. Technol., 39, 4441-4446, doi:10.1021/es048039h, 2005.

Lim, Y. B., Tan, Y., Perri, M. J., Seitzinger, S. P., and Turpin, B. J.: Aqueous chemistry and its role in secondary organic aerosol (SOA) formation, Atmos. Chem. Phys., 10, 1052110539, doi:10.5194/acp-10-10521-2010, 2010.

Marcolli, C. and Krieger, U. K.: Phase changes during hygroscopic cycles of mixed organic/inorganic model systems of tropospheric aerosols, J. Phys. Chem. A, 110, 1881-1893, doi:10.1021/jp0556759, 2006.

Maria, S. F., Russell, L. M., Gilles, M. K., and Myneni, S. C. B.: Organic aerosol growth mechanisms and their climate-forcing implications, Science, 306, 1921-1924, doi:10.1126/science.1103491, 2004.

Massoli, P., Lambe, A. T., Ahern, A. T., Williams, L. R., Ehn, M., Mikkilä, J., Canagaratna, M. R., Brune, W. H., Onasch, T. B., Jayne, J. T., Petäjä, T., Kulmala, M., Laaksonen, A., Kolb, C. E., Davidovits, P., and Worsnop, D. R.: Relationship between aerosol oxidation level and hygroscopic properties of laboratory generated secondary organic aerosol (SOA) particles, Geophys. Res. Lett., 37, L24801, doi:10.1029/2010GL045258, 2010.

McFiggans, G., Topping, D. O., and Barley, M. H.: The sensitivity of secondary organic aerosol component partitioning to the predictions of component properties - Part 1: A systematic evaluation of some available estimation techniques, Atmos. Chem. Phys., 10, 10255-10272, doi:10.5194/acp-10-10255-2010, 2010.
Moré, J. J., Garbow, B. S., and Hillstrom, K. E.: User Guide for MINPACK-1, Argonne National Laboratory Report ANL-80-74, Argonne, Ill., USA, http://www.netlib.org/minpack/, 1980.

Moré, J. J., Sorensen, D. C., Hillstrom, K. E., and Garbow, B. S.: The MINPACK Project, in Sources and Development of Mathematical Software, Prentice-Hall, Inc., Upper Saddle River, NJ, USA, 1984.

Müller, L., Reinnig, M.-C., Hayen, H., and Hoffmann, T.: Characterization of oligomeric compounds in secondary organic aerosol using liquid chromatography coupled to electrospray ionization Fourier transform ion cyclotron resonance mass spectrometry, Rapid Commun. Mass Spectrom., 23, 971-979, doi:10.1002/rcm.3957, 2009.

Odum, J. R., Hoffmann, T., Bowman, F., Collins, D., Flagan, R. C., and Seinfeld, J. H.: Gas/Particle Partitioning and Secondary Organic Aerosol Yields, Environ. Sci. Technol., 30, 2580-2585, 1996.

Pankow, J. F.: An absorption model of gas/particle partitioning of organic compounds in the atmosphere, Atmos. Environ., 28, 185-188, 1994.

Pankow, J. F.: Gas/particle partitioning of neutral and ionizing compounds to single and multi-phase aerosol particles. 1.Unified modeling framework, Atmos. Environ., 37, 3323-3333, doi:10.1016/S1352-2310(03)00346-7, 2003.

Pankow, J. F. and Asher, W. E.: SIMPOL.1: a simple group contribution method for predicting vapor pressures and enthalpies of vaporization of multifunctional organic compounds, Atmos. Chem. Phys., 8, 2773-2796, doi:10.5194/acp-8-27732008, 2008.

Pathak, R. K., Stanier, C. O., Donahue, N. M., and Pandis, S. N.: Ozonolysis of $\alpha$-pinene at atmospherically relevant concentrations: Temperature dependence of aerosol mass fractions (yields), J. Geophys. Res., 112, D03201, doi:10.1029/2006JD007436, 2007.

Pfrang, C., Shiraiwa, M., and Pöschl, U.: Chemical ageing and transformation of diffusivity in semi-solid multi-component organic aerosol particles, Atmos. Chem. Phys., 11, 7343-7354, doi:10.5194/acp-11-7343-2011, 2011.

Pöschl, U.: Gas-particle interactions of tropospheric aerosols: Kinetic and thermodynamic perspectives of multiphase chemical reactions, amorphous organic substances, and the activation of cloud condensation nuclei, Atmos. Res., 101, 562-573, doi:10.1016/j.atmosres.2010.12.018, 2011.

Press, W. H., Teukolsky, S. A., Vetterling, W. T., and Flannery, B. P.: Numerical Recipes 3rd Edition: The Art of Scientific Computing, Cambridge University Press, 3 edn., http://www.worldcat org/isbn/0521880688, 2007.

Pun, B. K. L., Griffin, R. J., Seigneur, C., and Seinfeld, J. H.: Secondary organic aerosol - 2. Thermodynamic model for gas/particle partitioning of molecular constituents, J. Geophys. Res. Atmos., 107, 4333, doi:10.1029/2001JD000542, 2002.

Pye, H. O. T. and Seinfeld, J. H.: A global perspective on aerosol from low-volatility organic compounds, Atmos. Chem. Phys., 10, 4377-4401, doi:10.5194/acp-10-4377-2010, 2010.

Reid, J. P., Dennis-Smither, B. J., Kwamena, N.-O. A., Miles, R. E. H., Hanford, K. L., and Homer, C. J.: The morphology of aerosol particles consisting of hydrophobic and hydrophilic phases: hydrocarbons, alcohols and fatty acids as the hydrophobic component, Phys. Chem. Chem. Phys., 13, 15559-15572, 
doi:10.1039/C1CP21510H, 2011.

Robinson, A. L., Donahue, N. M., Shrivastava, M. K., Weitkamp, E. A., Sage, A. M., Grieshop, A. P., Lane, T. E., Pierce, J. R., and Pandis, S. N.: Rethinking Organic Aerosols: Semivolatile Emissions and Photochemical Aging, Science, 315, 1259-1262, doi:10.1126/science.1133061, 2007.

Rudich, Y., Donahue, N. M., and Mentel, T. F.: Aging of Organic Aerosol: Bridging the Gap Between Laboratory and Field Studies, Annu. Rev. Phys. Chem., 58, 321-352, doi:10.1146/annurev.physchem.58.032806.104432, 2007.

Saunders, S. M., Jenkin, M. E., Derwent, R. G., and Pilling, M. J.: Protocol for the development of the Master Chemical Mechanism, MCM v3 (Part A): tropospheric degradation of nonaromatic volatile organic compounds, Atmos. Chem. Phys., 3, 161-180, doi:10.5194/acp-3-161-2003, 2003.

Shilling, J. E., Chen, Q., King, S. M., Rosenoern, T., Kroll, J. H., Worsnop, D. R., McKinney, K. A., and Martin, S. T.: Particle mass yield in secondary organic aerosol formed by the dark ozonolysis of $\alpha$-pinene, Atmos. Chem. Phys., 8, 2073-2088, doi:10.5194/acp-8-2073-2008, 2008.

Shilling, J. E., Chen, Q., King, S. M., Rosenoern, T., Kroll, J. H., Worsnop, D. R., DeCarlo, P. F., Aiken, A. C., Sueper, D., Jimenez, J. L., and Martin, S. T.: Loading-dependent elemental composition of $\alpha$-pinene SOA particles, Atmos. Chem. Phys., 9, 771-782, doi:10.5194/acp-9-771-2009, 2009.

Shiraiwa, M., Ammann, M., Koop, T., and Pöschl, U.: Gas uptake and chemical aging of semisolid organic aerosol particles, P. Natl. Acad. Sci. USA, 108, 11003-11008, doi:10.1073/pnas.1103045108, 2011.

Smith, M. L., Kuwata, M., and Martin, S. T.: Secondary Organic Material Produced by the Dark Ozonolysis of $\alpha$ Pinene Minimally Affects the Deliquescence and Efflorescence of Ammonium Sulfate, Aerosol Sci. Technol., 45, 244-261, doi:10.1080/02786826.2010.532178, 2011.

Song, C., Zaveri, R. A., Alexander, M. L., Thornton, J. A., Madronich, S., Ortega, J. V., Zelenyuk, A., Yu, X.-Y., Laskin, A., and Maughan, D. A.: Effect of hydrophobic primary organic aerosols on secondary organic aerosol formation from ozonolysis of a-pinene, Geophys. Res. Lett., 34, L20803, doi:10.1029/2007GL030720, 2007.

Song, M., Marcolli, C., Krieger, U. K., Zuend, A., and Peter, T.: Liquid-liquid phase separation and morphology of internally mixed dicarboxylic acids/ammonium sulfate/water particles, Atmos. Chem. Phys., 12, 2691-2712, doi:10.5194/acp-12-26912012, 2012.

Soonsin, V., Zardini, A. A., Marcolli, C., Zuend, A., and Krieger, U. K.: The vapor pressures and activities of dicarboxylic acids reconsidered: the impact of the physical state of the aerosol, Atmos. Chem. Phys., 10, 11753-11767, doi:10.5194/acp-1011753-2010, 2010.

Sullivan, A. P. and Weber, R. J.: Chemical characterization of the ambient organic aerosol soluble in water: 1 . Isolation of hydrophobic and hydrophilic fractions with a XAD-8 resin, J. Geophys. Res., 111, D05314, doi:10.1029/2005JD006485, 2006.

Surratt, J. D., Chan, A. W. H., Eddingsaas, N. C., Chan, M. N., Loza, C. L., Kwan, A. J., Hersey, S. P., Flagan, R. C., Wennberg, P. O., and Seinfeld, J. H.: Reactive intermediates revealed in secondary organic aerosol formation from isoprene, P. Natl. Acad. Sci., 107, 6640-6645, doi:10.1073/pnas.0911114107, 2010.
Tong, H.-J., Reid, J. P., Bones, D. L., Luo, B. P., and Krieger, U. K.: Measurements of the timescales for the mass transfer of water in glassy aerosol at low relative humidity and ambient temperature, Atmos. Chem. Phys., 11, 4739-4754, doi:10.5194/acp-11-47392011, 2011.

Topping, D., Lowe, D., and McFiggans, G.: Partial Derivative Fitted Taylor Expansion: an efficient method for calculating gas/liquid equilibria in atmospheric aerosol particles - Part 2: Organic compounds, Geosci. Model Dev., 5, 1-13, doi:10.5194/gmd-51-2012, 2012.

Topping, D. O., Lowe, D., and McFiggans, G.: Partial Derivative Fitted Taylor Expansion: An efficient method for calculating gas-liquid equilibria in atmospheric aerosol particles: 1. Inorganic compounds, J. Geophys. Res. Atmos., 114, D04304, doi:10.1029/2008JD010099, 2009.

Vaden, T. D., Imre, D., Beranek, J., Shrivastava, M., and Zelenyuk, A.: Evaporation kinetics and phase of laboratory and ambient secondary organic aerosol, P. Natl. Acad. Sci. USA, 108, 2190 2195, doi:10.1073/pnas.1013391108, 2011.

Valorso, R., Aumont, B., Camredon, M., Raventos-Duran, T., Mouchel-Vallon, C., Ng, N. L., Seinfeld, J. H., Lee-Taylor, J., and Madronich, S.: Explicit modelling of SOA formation from $\alpha$-pinene photooxidation: sensitivity to vapour pressure estimation, Atmos. Chem. Phys., 11, 6895-6910, doi:10.5194/acp-116895-2011, 2011.

Virtanen, A., Joutsensaari, J., Koop, T., Kannosto, J., Yli-Pirilä, P., Leskinen, J., Mäkelä, J. M., Holopainen, J. K., Pöschl, U., Kulmala, M., Worsnop, D. R., and Laaksonen, A.: An amorphous solid state of biogenic secondary organic aerosol particles, Nature, 467, 824-827, doi:10.1038/nature09455, 2010.

Zaveri, R. A., Easter, R. C., and Peters, L. K.: A computationally efficient Multicomponent Equilibrium Solver for Aerosols (MESA), J. Geophys. Res., 110, D24203, doi:10.1029/2004JD005618, 2005.

Zobrist, B., Marcolli, C., Pedernera, D. A., and Koop, T.: Do atmospheric aerosols form glasses?, Atmos. Chem. Phys., 8, 52215244, doi:10.5194/acp-8-5221-2008, 2008.

Zobrist, B., Soonsin, V., Luo, B.-P., Krieger, U. K., Marcolli, C., Peter, T., and Koop, T.: Ultra-slow water diffusion in aqueous sucrose glasses, Phys. Chem. Chem. Phys., 13, 3514-3526, doi:10.1039/C0CP01273D, 2011.

Zuend, A., Marcolli, C., Luo, B. P., and Peter, T.: A thermodynamic model of mixed organic-inorganic aerosols to predict activity coefficients, Atmos. Chem. Phys., 8, 4559-4593, doi:10.5194/acp8-4559-2008, 2008.

Zuend, A., Marcolli, C., Peter, T., and Seinfeld, J. H.: Computation of liquid-liquid equilibria and phase stabilities: implications for RH-dependent gas/particle partitioning of organic-inorganic aerosols, Atmos. Chem. Phys., 10, 7795-7820, doi:10.5194/acp10-7795-2010, 2010.

Zuend, A., Marcolli, C., Booth, A. M., Lienhard, D. M., Soonsin, V., Krieger, U. K., Topping, D. O., McFiggans, G., Peter, T., and Seinfeld, J. H.: New and extended parameterization of the thermodynamic model AIOMFAC: calculation of activity coefficients for organic-inorganic mixtures containing carboxyl, hydroxyl, carbonyl, ether, ester, alkenyl, alkyl, and aromatic functional groups, Atmos. Chem. Phys., 11, 9155-9206, doi:10.5194/acp11-9155-2011, 2011. 